\title{
Concussion and the autonomic nervous system: An introduction to the field and the results of a systematic review
}

\author{
Jon L. Pertab ${ }^{\mathrm{a}, *}$, Tricia L. Merkley ${ }^{\mathrm{b}}$, Alex J. Cramond ${ }^{\mathrm{c}}$, Kelly Cramond ${ }^{\mathrm{c}, \mathrm{d}}$, Holly Paxton ${ }^{\mathrm{e}}$ \\ and Trevor $\mathrm{Wu}^{\mathrm{e}}$ \\ ${ }^{\mathrm{a}}$ Neurosciences Institute, Intermountain Healthcare, Murray, UT, USA \\ ${ }^{\mathrm{b}}$ Department of Clinical Neuropsychology, Barrow Neurological Institute, Phoenix, AZ, USA \\ ${ }^{\mathrm{c}}$ Summit Neuropsychology, Reno, NV, USA \\ ${ }^{\mathrm{d}}$ VA Sierra Nevada Healthcare System, Reno, NV, USA \\ ${ }^{\mathrm{e}}$ Hauenstein Neurosciences of Mercy Health and Department of Translational Science \\ and Molecular Medicine, Michigan State University, MI, USA
}

\begin{abstract}
.
BACKGROUND: Recent evidence suggests that autonomic nervous dysfunction may be one of many potential factors contributing to persisting post-concussion symptoms.

OBJECTIVE: This is the first systematic review to explore the impact of concussion on multiple aspects of autonomic nervous system functioning.

METHODS: The methods employed are in compliance with the American Academy of Neurology (AAN) and PRISMA standards. Embase, MEDLINE, PsychINFO, and Science Citation Index literature searches were performed using relevant indexing terms for articles published prior to the end of December 2016. Data extraction was performed by two independent groups, including study quality indicators to determine potential risk for bias according to the 4-tiered classification scheme of the AAN.

RESULTS: Thirty-six articles qualified for inclusion in the analysis. Only three studies (one Class II and two Class IV) did not identify anomalies in measures of ANS functioning in concussed populations.

CONCLUSIONS: The evidence supports the conclusion that it is likely that concussion causes autonomic nervous system anomalies. An awareness of this relationship increases our understanding of the physical impact of concussion, partially explains the overlap of concussion symptoms with other medical conditions, presents opportunities for further research, and has the potential to powerfully inform treatment decisions.
\end{abstract}

Keywords: Concussion, mild traumatic brain injury, post-concussion syndrome, autonomic dysfunction, orthostatic intolerance

\section{Introduction}

\subsection{Mild traumatic brain injury and postconcussive symptoms}

For every 100,000 people in the population, about 500 people a year present to an emergency

\footnotetext{
*Address for correspondence: Jon L. Pertab, Ph.D., Neurosciences Institute, Intermountain Healthcare, 5171S Cottonwood St. Ste. 810, Murray, UT 84107, USA. Tel.: +1 801507 9800; Fax: +1 801507 9801; E-mail: jon.pertab@imail.org.
}

department with mild traumatic brain injury (mTBI)/concussion (Bazarian et al., 2005). The actual prevalence of concussions is likely much higher than this figure, as only about a third of patients with concussion present for acute treatment in emergency departments; some present to primary care or urgent care clinics, and many do not seek any medical intervention (Feigin et al., 2013; Sosin, Sniezek, \& Thurman, 1996). A number of symptoms are associated with concussive injuries including headache, nausea, balance difficulties, light and noise 
sensitivity, cognitive difficulties, sleep disruption, and emotional disturbance (de Guise et al., 2010; Elbin et al., 2016; Landre, Poppe, Davis, Schmaus, \& Hobbs, 2006; Oldenburg, Lundin, Edman, Nygren-de Boussard, \& Bartfai, 2016).

There is wide variance in the persistence of postconcussion symptoms dependent on the mechanism of injury and nature of the population sampled. For example, in a sports concussion sample of 635 high school and collegiate athletes, less than 3\% reported lingering symptoms at one month post injury (McCrea et al., 2009). A very different picture is seen in patients who present to emergency departments with concussions from a mixed variety of mechanisms. In emergency department concussion studies from around the globe, the prevalence of persisting symptoms at 6 months or more ranges from about 30-50\% (Canada - (Bellerose, Bernier, Beaudoin, Gravel, \& Beauchamp, 2017); Sweden - (Ahman, Saveman, Styrke, Bjornstig, \& Stalnacke, 2013; Lannsjo, af Geijerstam, Johansson, Bring, \& Borg, 2009); Morocco - (Fourtassi et al., 2011); Netherlands - (de Koning et al., 2017; Stulemeijer, van der Werf, Borm, \& Vos, 2008); Norway - (Jakola et al., 2007; Roe, Sveen, Alvsaker, \& Bautz-Holter, 2009; Sigurdardottir, Andelic, Roe, Jerstad, \& Schanke, 2009); Germany - (Rickels, von Wild, \& Wenzlaff, 2010); China - (Chan, 2005); Lithuania - (Mickeviciene et al., 2004); Switzerland - (Zumstein et al., 2011); England - (Barrett, Ward, Boughey, Jones, \& Mychalkiw, 1994); United States - (Kraus, Hsu, Schafer, \& Afifi, 2014; McMahon et al., 2014; Rimel, Giordani, Barth, Boll, \& Jane, 1981); India - (Gururaj, 2002); Scotland - (Thornhill et al., 2000); New Zealand - (Norrie et al., 2010; Theadom et al., 2016)).

Identifying the cause of this high prevalence of persistent post-concussive symptoms in the non-sports population has been a source of much speculation. Some of the most cited reasons for persistent complaints after concussion include:

- Persistent central nervous system neuropathology (Bigler et al., 2016; D'Souza M et al., 2015; Dean, Sato, Vieira, McNamara, \& Sterr, 2015; Nordin et al., 2016; Shahim et al., 2017; Zagorchev et al., 2016)

- Malingering (Carroll et al., 2004; Cottingham \& Boone, 2014; Lange, Iverson, Brooks, \& Rennison, 2010; Spadoni, Kosheleva, Buchsbaum, \& Simmons, 2015)

- Expectation effects (Ferguson, Mittenberg, Barone, \& Schneider, 1999; Waldron-Perrine, Tree, Spencer, Suhr, \& Bieliauskas, 2015)
- Psychological conditions either preceding or subsequent to the injury (Donnell, Kim, Silva, \& Vanderploeg, 2012; Losoi et al., 2016; Macleod, 2010)

- Posttraumatic anxiety responses (Bryant, 2011; Schneiderman, Braver, \& Kang, 2008; Vasterling et al., 2012)

- Pituitary Dysfunction (Sundaram, Geer, \& Greenwald, 2013; Tanriverdi et al., 2015; Tanriverdi, Unluhizarci, \& Kelestimur, 2010)

- Vestibular or oculomotor dysfunction (Heitger et al., 2009; Suh et al., 2006)

- Chronic pain and/or comorbid injuries to the cervical spine (Morin, Langevin, \& Fait, 2016; Richter, 1995; Smith-Seemiller, Fow, Kant, \& Franzen, 2003; Weyer Jamora, Schroeder, \& Ruff, 2013)

In considering the question of the causation of postconcussive symptoms, we would echo the conclusions of Iverson over a decade ago: "Those seeking simplistic answers for the underlying cause of the postconcussion syndrome (e.g., 'neurogenic' versus 'psychogenic') can easily find superficial support for binary or interwoven etiologies in the extant literature. The literature is large, convoluted, methodologically flawed, and the conclusions drawn frequently go well beyond the empirical data. Experienced clinicians and researchers know that it is extraordinarily difficult to disentangle the many factors that can be related to self-reported symptoms in persons who have sustained remote MTBIs [mild traumatic brain injuries/concussions]." (Iverson, 2005)

Dysfunction of the autonomic nervous system (ANS) has also been proposed as a factor that can contribute to postconcussive complaints (J. Leddy, Hinds, Sirica, \& Willer, 2016; J. J. Leddy, Kozlowski, Fung, Pendergast, \& Willer, 2007). The purpose of the present paper is to introduce the reader to aspects of ANS physiology that are relevant in concussion recovery and systematically review literature that directly explores ANS dysfunction in concussed humans. This article is organized in three main sections: 1) a brief overview of the ANS, and in particular its relevance in cerebral perfusion and concussion, 2) the results of a systematic review designed to identify articles exploring ANS dysfunction in humans with concussive injuries, and 3) conclusions based on the systematic review including a brief outline of treatment implications gleaned from increased understanding of the ANS-concussion relationship. The present paper is the first systematic review to explore 
the impact of concussion on multiple aspects of ANS functioning.

\subsection{The autonomic nervous system: A brief overview}

When compared to other neural processes, the role of the ANS in human health has been comparatively neglected in clinical research and training programs (Beissner \& Baudrexel, 2014; Rees, 2014). For many rehabilitation professionals, training regarding the workings of the ANS tends to be focused on the fight-flight and rest-digest aspects of the sympathetic (SNS) and parasympathetic (PNS) branches of the autonomic nervous system respectively. While these ANS functions are certainly important, they represent only a small subset of the many ways that the ANS contributes to human physical functioning.

The ANS innervates cardiac muscle, smooth muscle, and glands in organ systems throughout the body. It supports the automated fine-tuning of organ systems to maintain an adaptive response to changes in the internal and external environment (such as changes in levels of temperature, light exposure, or level of threat). It also regulates organ systems to respond optimally to changes in behavior (such as feeding, postural changes, and sexual encounters). The ANS plays a role in regulating blood pressure, gastrointestinal movement and secretion, body temperature, metabolism, sexual response, glucose metabolism, and many other physical processes. If ANS fibers to an organ are cut, the organ may continue to function, but capacity to respond to changing conditions will be compromised (Robertson, 2004).

It should be noted that the ANS works in concert with the hypothalamic-pituitary-adrenal axis and has intricate feedback loops with other body systems such as the immune system (Elenkov, Wilder, Chrousos, \& Vizi, 2000; Kenney \& Ganta, 2014; Ulrich-Lai \& Herman, 2009). Elaborating on these intertwined systemic relationships is beyond the scope of this paper but their existence reinforces the concept that human physiology is best conceptualized holistically, as an integrated network of organs and functions rather than disparate semi-independent systems.

\subsection{The ANS and cerebral perfusion}

One of the roles of the ANS is to regulate the diameter of blood vessels that contain smooth muscle. In general, sympathetic activation acts to constrict blood vessels while parasympathetic activation dilates vessels. This process impacts organs and structures throughout the body, including the flow of blood in the brain (cerebral perfusion).

The ANS is not the only system that impacts cerebral blood flow. Other processes involved include vaso-neuronal coupling (a link between the metabolic needs of neuronal networks and changes in the diameter of the blood vessels that supply them), cerebral blood vessel response to varying levels of localized circulating carbon dioxide and oxygen, pericite-mediated changes in neural capillary diameter, and direct/intrinsic innervation of cerebral blood vessels from structures in the central nervous system (CNS) (see reviews in Bishop \& Neary, 2015; Folino, 2007; Goadsby, 2004; Tahsili-Fahadan \& Geocadin, 2017).

While not the only system involved in cerebral perfusion, the ANS does play a prominent role, and also interacts with other systems known to regulate cerebral perfusion. There are two main aspects to ANS regulation of cerebral perfusion, 1) a system to maintain tolerances of overall blood pressure entering the brain based on ANS modulation of cardiac functioning (the baroreflex), and 2) extrinsic innervation of surface cerebral blood vessels by the ANS.

\subsubsection{The baroreflex}

The baroreflex is a term that refers to an ANS feedback loop that maintains stable blood flow into brain tissue. The carotid arteries contain baroreceptors, which are sensory neurons whose firing rates are linked to the level of stretch in the arterial wall. These receptors provide input regarding carotid blood pressure to the nucleus of the solitary tract in the brain stem and from there to additional brain regions that are involved in ANS responses (nucleus ambiguus, the dorsal motor nucleus, and the caudal and rostral ventrolateral medulla oblongata). When pressure in the carotid arteries changes, signals are sent from the brain via parasympathetic and sympathetic ANS pathways to the sinus node of the heart, heart muscle, and vasculature. These signals serve to increase or decrease heart rate and contractility, and change the tone and diameter of blood vessels - thus altering vascular resistance (for further details, see the review by Duschek, Werner, \& Reyes Del Paso, 2013). The combined effect of these reflexes is to maintain a stable pressure in arteries supplying blood to the brain. 


\subsubsection{Extrinsic innervation of surface cerebral blood vessels}

"The brain possesses an intrinsic mechanism by which its vascular supply can be varied locally in correspondence with local variations of functional activity." (Roy \& Sherrington, 1890)

Once blood enters the brain, there are systems in place to increase perfusion to networks that are highly active in current demands and decrease perfusion to brain areas that are less relevant to the circumstances at hand. At this very moment, the ANS in concert with other processes is promoting preferential blood supply to networks in your brain that optimizes your capacity to efficiently read and process what you are reading (and down-regulate supply to networks that are less active).

As previously mentioned, there are numerous processes that contribute to region specific variation in cerebral blood flow. One of the prominent processes reflects ANS activity. Direct innervation of cerebral blood vessels by the ANS is primarily localized to the surface of the brain. Cerebral arteries and arterioles constrict in response to sympathetic nerve stimulation, and parasympathetic activation acts as a vasodilator. When cerebral arteries enter brain parenchyma there is a transition to intrinsic CNS innervation by structures in the locus coeruleus, raphe nucleus, basal forebrain, and thalamus (Folino, 2007). It is notable that many of these structures share involvement in central nervous system control of the autonomic nervous system (Benarroch, 1993; McDougall, Munzberg, Derbenev, \& Zsombok, 2014; Taggart, Critchley, van Duijvendoden, \& Lambiase, 2016; Takahashi, Hinson, \& Baguley, 2015). This suggests that both surface and internal brain blood vessel innervation is controlled by a single system served by core CNS networks that are involved in ANS regulatory functions. Some of the afferents of these networks connect to cerebral blood vessels via standard ANS fiber tracts and some take a more direct internal route.

The ANS is one of the systems that increase the efficiency of the brain by increasing blood supply to brain networks that are best suited to task demands. This allows the brain to perform optimally for periods of time that would otherwise be prohibitive if resource availability (via the blood) was not facilitated by this dynamic process.

\subsection{The relevance of cerebral perfusion in concussion}

Alterations in cerebral blood flow have been identified as one of the most lingering metabolic changes associated with animal models of concussion (Giza $\&$ Hovda, 2014). Anomalies in cerebral blood flow have also been found in human samples of concussed patients; anomalies may persist for weeks and months post-injury, and such anomalies correlate with persistent postconcussive complaints (Barlow et al., 2017; Bartnik-Olson et al., 2014; Bonne et al., 2003; N. Churchill et al., 2017; N. W. Churchill et al., 2017; Clausen, Pendergast, Willer, \& Leddy, 2016; Ellis et al., 2016; Gardner et al., 2015; Maugans, Farley, Altaye, Leach, \& Cecil, 2012; Meier et al., 2015; Mutch et al., 2016; Sours, Zhuo, Roys, Shanmuganathan, \& Gullapalli, 2015; Y. Wang et al., 2016).

\subsection{Cerebral perfusion and postconcussive complaints in non-concussed samples}

Symptoms associated with concussion are nonspecific to concussion. Many medical conditions present with postconcussive-type complaints at levels that equal or even exceed the level observed in patients with concussion. Those conditions that have been directly evaluated for the presence of postconcussive complaints include:

- chronic pain (Gasquoine, 2000; Smith-Seemiller et al., 2003)

- stress (Machulda, Bergquist, Ito, \& Chew, 1998)

- depression (Donnell et al., 2012; Garden, Sullivan, \& Lange, 2010; Trahan, Ross, \& Trahan, 2001)

- anxiety (Donnell et al., 2012; Garden et al., 2010; Lagarde et al., 2014)

- chronic fatigue syndrome (Tiersky, Cicerone, Natelson, \& DeLuca, 1998)

- orthopedic injuries (Laborey et al., 2014; Landre et al., 2006; Losoi et al., 2016; Mickeviciene et al., 2004)

- sleep disruption (Stocker, Khan, Henry, \& Germain, 2017)

A portion of the general population also reports concussion-like complaints (Iverson \& Lange, 2003; Wong, Regennitter, \& Barrios, 1994). Patients with cervical strain injuries have symptom profiles that are often indistinguishable from patients with concussion (Morin et al., 2016). 
What factor can account for the similarities of complaints amongst these diverse groups and patients with concussion?

Part of the answer may lie in the observation that autonomic dysregulation has been identified in many of these conditions, including:

- chronic pain (Fazalbhoy, Birznieks, \& Macefield, 2014; Hallman \& Lyskov, 2012; Koenig, Jarczok, Ellis, Hillecke, \& Thayer, 2014)

- insomnia (Basta, Chrousos, Vela-Bueno, \& Vgontzas, 2007; Farina et al., 2014; Huang, Kutner, \& Bliwise, 2011; Maes et al., 2014; Spiegelhalder et al., 2011; Vgontzas et al., 1998)

- stress (Chrousos, 2009; Tsigos, Kyrou, Kassi, \& Chrousos, 2000)

- deconditioning (Convertino, Doerr, Eckberg, Fritsch, \& Vernikos-Danellis, 1990; Coupe et al., 2009; Pawelczyk, Zuckerman, Blomqvist, \& Levine, 2001)

- depression (Bassett, 2016; Perlmuter et al., 2012; Won \& Kim, 2016)

- anxiety (Brudey et al., 2015; Friedman \& Thayer, 1998; Hoehn-Saric \& McLeod, 1988; McCraty, Atkinson, Tomasino, \& Stuppy, 2001; Thayer, Friedman, \& Borkovec, 1996)

- chronic fatigue syndrome and fibromyalgia (Elenkov et al., 2000; Kulshreshtha \& Deepak, 2013; Lee et al., 2016)

- Cervical strain/whiplash-associated disorders (Sterling, 2011).

As previously noted, ANS dysregulation has the potential to impact baroreflex efficiency and cerebral perfusion. It is thus not surprising that in many of the conditions listed above, anomalies in indices of cerebral perfusion and baroreflex efficiency have also been found:

- chronic pain (Coghill, Sang, Berman, Bennett, \& Iadarola, 1998; Duschek, Muck, \& Reyes Del Paso, 2007; Gilkey, Ramadan, Aurora, \& Welch, 1997; Nagamachi et al., 2006; Sundstrom et al., 2006)

- insomnia (Smith et al., 2002; Smith, Perlis, Chengazi, Soeffing, \& McCann, 2005)

- deconditioning (Kawai et al., 1993; Sun et al., 2005)

- depression (Koschke et al., 2009; MacHale et al., 2000; Vasic et al., 2015)

- anxiety (Fredrikson, Fischer, \& Wik, 1997; Hughes, Feldman, \& Beckham, 2006; Lambert et al., 2002; Mathew, 1994)
- chronic fatigue syndrome (MacHale et al., 2000; Peckerman et al., 2003; Yoshiuchi, Farkas, \& Natelson, 2006)

It is also of note, that patients with known baroreflex dysfunction as their primary diagnosis (such as postural orthostatic tachycardia syndrome) report symptoms similar to those reported by patients with concussion, including fatigue, headaches, nausea, memory dysfunction, attention complaints, brain fog, anxiety, depression, and insomnia (Arnold et al., 2015; Garland, Celedonio, \& Raj, 2015; Ocon, 2013; Ross, Medow, Rowe, \& Stewart, 2013).

The research briefly reviewed above supports the contention that a contributor to the symptoms associated with concussion may be ANS anomalies and their associated impact on cerebral blood flow efficiency. With this in mind, it is not surprising that the symptoms of concussion are non-specific to concussion and occur in many other medical conditions that involve ANS dysfunction and compromised cerebral blood flow efficiency. The present article systematically evaluates the literature that explores the impact of human concussion on the ANS.

\subsection{Measurement of the autonomic nervous system}

The ANS can be measured in multiple ways. In this section we discuss the most common measurement techniques that appear in concussion research.

\subsubsection{Heart rate variability $(H R V)$}

Heart rate variability is one of the most commonly used techniques to evaluate the functioning of the ANS in concussion-related studies. The use of HRV as a measure of autonomic functioning is based on the observation that pacemakers in the heart are regulated by input from both the SNS and PNS - the baroreflex (Rajendra Acharya, Paul Joseph, Kannathal, Lim, \& Suri, 2006). Heart rate variability reflects the fact that the period of time between any two consecutive heart beats (R-R intervals) is not exactly the same; largely due to SNS and PNS regulation. When we say a person has a heart rate of 60 beats per minute we are reporting an average, around which there is variability (HRV). Simplistically, the SNS is thought to increase heart rate and decrease HRV whereas the PNS is thought to slow heart rate and increase HRV. In practice, both branches of the ANS work together in harmony to regulate heart rate and HRV in order to optimize heart output to situational demands. In severe 
traumatic brain injury there is an "uncoupling" of pacemakers located in heart tissue and ANS input to the heart; this uncoupling is more pronounced in patients with the most severe injuries; for patients in a coma, HRV can approach zero (Goldstein, Toweill, Lai, Sonnenthal, \& Kimberly, 1998). Standard procedures, definitions, and interpretations for HRV analysis were established by the Task Force of the European Society of Cardiology and the North American Society of Pacing and Electrophysiology (1996).

\subsubsection{Valsalva maneuver (VM)}

The Valsalva maneuver can be used to evaluate the responsiveness of sympathetic and parasympathetic baroreflex pathways to changes in intrathoracic pressure (Low, Tomalia, \& Park, 2013; Novak, 2011). Participants blow into a mouthpiece connected to a pressure monitor and are instructed to maintain a predetermined pressure for 15 seconds. Changes in blood pressure, heart rate, and heart rate variability are used to quantify the response of the baroreflex.

\subsubsection{Head upright tilt table testing (HUT)}

Head upright tilt table testing provides an evaluation of the blood pressure and heart rate response to tilt and is used to detect orthostatic hypotension (failure of the baroreflex to maintain stable cerebral blood pressure in response to postural stasis and positional change) (Low et al., 2013; Novak, 2011). Alternative, indirect methods to measure baroreflex impairment to postural challenge include tracking for symptoms of syncope (fainting) and pre-syncopal symptoms (such as visual symptoms or lightheadedness when standing).

\subsubsection{Cerebral perfusion in response to manipulation of blood pressure}

The rate of blood flow in major vessels in the brain can be measured by transcranial doppler ultrasonography (TCD) and other methods such as arterial spin labeling MRI techniques. Experimental manipulation of systemic blood pressure using either medications or deflation of pressurized leg cuffs activates baroreflex-mediated adaptations to maintain stable cerebral blood flow. Changes in cerebral perfusion measured by TCD quantify the efficiency of the baroreflex response.

\subsubsection{Sympathetic response to stress}

The sympathetic nervous system can be stimulated by applying physical stressors (such as exercise or pain), or environmental stressors (cold or loud noise).
ANS-mediated changes in heart rate and sweating (skin conductance) can be directly measured and contrasted with control groups to identify atypical autonomic responses.

\subsubsection{Oculocardiac reflex}

Applying standardized pressure to the eyeball triggers a series of impulses in ANS pathways with the end results of increasing parasympathetic input to the heart, which is known as the oculocardiac reflex. The strength of this response can be measured by heart rate indices and $\mathrm{HRV}$ analysis.

\subsubsection{Arterial pulse wave}

Increasing peripheral SNS tone (which decreases blood vessel lumen diameter) alters the magnitude and latency of reflected waves from blood being pumped from the heart into arteries. Wave pattern analysis can identify atypical responses of the ANS to changes in vascular resistance.

\subsubsection{Pupillary response to light exposure}

The ANS is the dominant regulator of pupil diameter with SNS activation leading to dilation and PNS activation leading to constriction of the pupil (McDougal \& Gamlin, 2015). Medical devices have been developed to measure the latency, amplitude, and speed of pupil changes in response to bursts of light of various frequencies and durations.

\section{Methods}

The review was designed to be consistent with the PRISMA (Preferred Reporting Items for Systematic reviews and Meta-Analyses) standards for conducting systematic reviews (Liberati et al., 2009; Moher, Liberati, Tetzlaff, Altman, \& Group, 2009). The American Academy of Neurology (AAN) has published specific methodology for conducting systematic reviews and evaluating the quality of identified research evidence $(2015 ; 2011)$. The methods employed in the present study are in compliance with the AAN, PRISMA, and the Institute of Medicine's standards for developing systematic reviews. A review protocol was not published prior to conducting the present review.

\subsection{Research question}

The AAN identifies several types of questions that form the foundation of the review methodology. The 
present topic of interest is classified as a causation question - "a question regarding the cause-and-effect relationship of an exposure and a condition." p.5.

Causation questions can be framed in the recommended (population, intervention, co-intervention, outcome, study designs sampled) PICOS format. The following question is examined in this review:

\footnotetext{
Population - In humans, Intervention - does a history of concussion Co-intervention - when compared to humans with no history of concussion
}

Outcome - cause anomalies in autonomic nervous system functioning.

Study Designs - No limitations were placed on timeframes post-injury or types of study design included in the analysis.

\subsection{Search strategy}

The search was conducted with the support of a medical librarian. Four electronic databases were utilized - Embase (1974-2016), MEDLINE (1950-2016), PsycINFO (1872-2016), and Science Citation Index (1900-2016). A preliminary search was conducted to retrieve articles of interest, and these were combined with articles from the private collection of the authors to identify key articles relevant to the research question. Medical subject headings used in indexing each of the key articles were identified for each database and were employed in the final search. Terms relevant to concussion were combined with the operator OR, as were terms associated with the autonomic nervous system.

The final search was conducted on December 28, 2016 with automated updates to the search to capture articles published (including advance online publication ahead of print) at any point prior to the end of December 2016. A Boolean search strategy comprising (condition of interest) AND (outcome of interest) was employed which utilized the following structure:

\section{(concussion) AND (autonomic nervous system)}

Relevant indexing terms were combined to produce a search string unique to each database. No limits (e.g. human, timeframes, article type) were employed. Search results were exported and combined using Endnote software with removal of duplicates. Key articles in the field were identified from the results of the initial search. The capacity of the final search to identify all of the key articles was used as a means to check the validity of the results. The search was refined until all key articles were identified. Furthermore, reference lists of review articles in the field and all articles reviewed in full text stage were manually searched to identify any additional relevant articles. The results of the database search, the reference lists of articles that were evaluated for full text review, and the personal collections of the authors were the only sources of information used to identify potentially relevant articles.

The results of the separate database searches were combined using Endnote software and duplicates removed. The resultant titles and abstracts were reviewed independently (TM and JP) to exclude clearly irrelevant articles. For articles deemed potentially relevant after title and abstract review, full text articles were retrieved and reviewed to determine if the article met the a priori inclusion-exclusion criteria.

Pre-specified inclusion-exclusion criteria that were used to identify articles relevant to the question at hand were:

1) Full text article published in a peer reviewed medical journal presenting original data. Excluded review articles summarizing the work of others, excluded abstracts without full text, and excluded published poster abstracts.

2) Data pertains to human subjects (any age included).

3) Data includes analysis of a group diagnosed with concussion. When mixed brain injury samples were studied, it was required that results be provided separately for a subgroup of participants with concussion (no mixed mildmoderate-severe groups).

4) Data includes at least one variable assessing the functioning of the autonomic nervous system. The outcome of interest was required to be primarily reflective of an autonomic process. Studies with outcomes that have multiple potential contributors, rendering doubt as to whether the ANS was the dominant contributor, were excluded. For example, the bulk of concussion related blood flow studies (e.g., SPECT) that did not also incorporate some form of autonomic challenge were excluded due to the numerous processes that could account for cerebral blood flow anomalies (see previous discussion).

The full text of all articles that met the inclusion-exclusion criteria were forwarded to two independent groups (KC/AC and TW/HP). For each article, both groups independently extracted study 
characteristics and entered these into an evidence table. Evidence tables summarized key components of each study - sample demographics and description, time since injury, concussion definition, ANS variables employed, results, conclusions; and tabulated characteristics relevant to generalizability, risk of bias, and findings (see below). The evidence table headings and structure was developed and piloted on a sample of articles prior to distribution to the independent extraction groups (by JP and TM).

The evidence tables included features of the study design that were relevant in determining risk of bias according to the four-tiered classifications scheme developed by the American Academy of Neurology. "In this scheme, studies graded Class I are judged to have a low risk of bias, studies graded Class II are judged to have a moderate risk of bias, studies graded Class III are judged to have a moderately high risk of bias, and studies graded Class IV are judged to have a very high risk of bias."

In the case of causation questions, for studies to be classified as Class I, they must meet the following criteria (AAN 2015):

- "Cohort survey with prospective data collection

- All relevant confounding characteristics are presented and substantially equivalent between comparison groups or there is appropriate statistical adjustment for differences

- Outcome measurement is objective or determined without knowledge of risk factor status

- Also required:

a. Primary outcome(s) defined

b. Exclusion/inclusion criteria defined

c. Accounting of dropouts (with at least $80 \%$ of enrolled subjects completing the study)"

Failure to meet these Class I requirements results in downgrading to lower classifications based on criteria defined by the AAN workgroup. To reduce subjectivity in criteria ratings several variables were operationalized to support consistent and accurate categorization. Operationalized definitions were provided to the two rating groups, the most prominent being defining what constituted adequate definition of the variables of interest (concussion and ANS) and definitions to clarify categorization of study designs (see below).

The group decided that an adequate definition of concussion must be consistent with those published by a recognized health organization (e.g. World Health Organization, Department of Defense, or
American Congress of Rehabilitation Medicine etc.). Definitions of concussion based solely on Glasgow Coma Score of 13 to 15 were considered inadequate as most accepted definitions used in research and clinical practice require additional features. People who have Glasgow Coma Scale scores of 15 may or may not have sustained a concussion dependent on the presence of mental status changes or symptoms indicative of brain impairment. Diagnostic methods where criteria were unstated, such as "diagnosis was made by clinical evaluation by medical staff" (in the absence of a statement regarding what specific criteria were employed) were also considered inadequate.

For the purpose of the present research, the types of studies were defined as follows:

Prospective cohort survey - Study participants (e.g., athletes) were enrolled prior to the development of the onset of the variable of interest (ANS dysfunction) and this is established via baseline testing. The population is split into groups based on exposure to the risk variable (concussion) and these two groups are followed for later emergence of the outcome of interest (ANS dysfunction). The AAN guideline requires "prospective data collection;" thus, if participants were recruited prior to their injury but no baseline data regarding ANS functioning was collected at baseline (pre-concussion) they were classified as retrospective cohort surveys.

Retrospective cohort survey - Participants are enrolled after they are assumed to have developed the outcome of interest (ANS dysfunction). The subsequent testing is designed to confirm the outcome or clarify its magnitude. In the case of concussion research, any designs where participants were first tested for ANS dysfunction after their concussive injury would fall into this category; present ANS dysfunction is associated with the prior (retrospective) exposure to the risk factor (concussion).

Case control study - A design that samples a population for the presence of the outcome (ANS dysfunction) and groups participants based on the presence or absence of the outcome (e.g. undergraduate psychology students are split into ANS dysfunction positive group compared to ANS dysfunction negative group). It is the presence of the outcome that determines group membership not concussion exposure (i.e. ANS cases vs. ANS noncases). The analysis involves determining what proportion of the cases and controls were exposed to the variable of interest (concussion).

The AAN guidelines include a criterion regarding confounding characteristics. For Class I studies 
confounds must be presented, equivalent, or adjusted for. For the present analysis, studies which employed close matching criteria were judged to have adequately met this criterion. Studies that evaluated and reported confound equivalence or statistically adjusted for these were also judged to have met the criteria.

As the two groups independently completed the evidence tables they were forwarded in stages to a third party not directly involved in the extraction (TM) for comparison. Any discrepancies were resolved by a consensus discussion coordinated by the third party - the two reviewing groups did not have direct contact with one another regarding their ratings. Once discrepancies were resolved, a final master evidence table was generated which forms the basis of the study results.

\subsection{Analysis}

For those articles that met inclusion criteria, quality of evidence was evaluated by employing the qualitative and quantitative tools described in the AAN guideline. The guideline includes processes for evaluating both the risk of bias in individual studies (grading criteria) and also at the outcome/conclusion level (how to temper and describe conclusions based on the entire sample). These processes are described in more detail in the body of the results section.

A principal summary measure for autonomic functioning evaluation was not employed due to the heterogeneity of methods employed in concussion research and the limited, early stage of research in this field. Any ANS outcome reported in patients with concussion was included for evaluation and whenever possible, differences in means between control and concussed groups on ANS variables were calculated.

\section{Results}

The search terms employed in the final search are listed in Table 1. The search gleaned 3159 articles from Embase, 2538 articles from MEDLINE, 106 from PsycINFO, and 88 from the Science Citation Index. These were combined in Endnote software and duplicates removed leaving 5382 articles identified as potentially relevant from the literatures search. A summary of the disposition of articles identified in the search is contained in Fig. 1.

Thirty-six studies were identified for inclusion in the analysis. Four of these were case studies, seven were case series, and 25 included a control group. All of the studies that included a control group were retrospective cohort designs. Quality indices and AAN grading for studies including a control group are summarized in Table 2. (Case studies and case series are automatically graded as Class 4 under AAN criteria).

\subsection{Conclusions regarding autonomic nervous system anomalies in concussion}

No Class I studies exploring the relationship between concussion and ANS anomalies were identified. For those studies that included a control group, the evidence base using AAN grading criteria included: Class II -7 studies, Class III -5 studies, and Class IV - 13 studies; with an additional 11 Class IV case studies or case series. The vast majority of the included studies identified anomalies in measures of ANS functioning in concussed populations. Only three studies (one Class II, and two Class IV) (Su, Kuo, Kuo, Lai, \& Chen, 2005; Temme, St Onge, \& Bleiberg, 2016; Truong \& Ciuffreda, 2016c) did not find a difference in autonomic measures between the sample of concussed patients and their respective control group. The four case studies, and seven case series all identified ANS anomalies in concussed individuals.

The AAN guidelines include a system for synthesizing evidence based on the overall quality of the multiple studies included in the analysis (an outcome level analysis). The system enables authors to use a common conclusion language to describe the synthesis of their results. Under AAN criteria, multiple class one studies warrant the use of a "highly likely" descriptor to describe the relationship between the variables. Two Class II studies or a single class I study corresponds to a "likely" conclusion. Further criteria are defined for data sets where a "possibly" or "insufficient evidence" conclusion is warranted. Per the AAN guidelines, the evidence base included in the present analysis supports the following conclusion for the outcome level analysis:

\section{It is "likely" that concussion causes autonomic nervous system anomalies.}

\subsection{Insights from uncontrolled studies}

Key characteristics of the case studies and case series are summarized in Table 3. It is not possible to draw systematic conclusions regarding causation from uncontrolled studies that are automatically 
Table 1

Indexing terms employed in the final search

\begin{tabular}{|c|c|}
\hline Concussion headings & Autonomic nervous system headings \\
\hline \multicolumn{2}{|l|}{$\overline{M E D L I N E}(\mathrm{MeSH})$} \\
\hline Brain injuries & Autonomic nervous system \\
\hline Brain concussion & Autonomic nervous system diseases \\
\hline \multirow[t]{5}{*}{ Postconcussion syndrome } & $\begin{array}{l}\text { Postural orthostatic tachycardia syndrome } \\
\text { Hypotension, orthostatic }\end{array}$ \\
\hline & Hemodynamics \\
\hline & Baroreflex \\
\hline & Blood flow velocity \\
\hline & Syncope \\
\hline \multicolumn{2}{|l|}{ Embase (Emtree) } \\
\hline Head Injury & Autonomic nervous system \\
\hline Brain Injury & Autonomic dysfunction \\
\hline Brain concussion & Orthostatic intolerance \\
\hline Postconcussion syndrome & Postural orthostatic tachycardia \\
\hline Traumatic brain injury & syndrome \\
\hline Concussion & Autoregulation \\
\hline \multirow[t]{4}{*}{ Brain Concussion } & Cardiovascular autoregulation \\
\hline & ECG abnormality \\
\hline & Heart Rate \\
\hline & Heart rate variability \\
\hline \multicolumn{2}{|l|}{ PsycINFO (Subjects) } \\
\hline Brain Concussion & Autonomic nervous system \\
\hline \multirow[t]{4}{*}{ Traumatic brain injury } & Sympathetic nervous system \\
\hline & Parasympathetic nervous system \\
\hline & Syncope \\
\hline & Heart rate \\
\hline \multicolumn{2}{|l|}{ Science Citation Index (Topics) } \\
\hline Concussion & Autonomic \\
\hline Postconcussion syndrome & Autonomic control \\
\hline Mild traumatic brain injury & Autonomic dysfunction \\
\hline Concussion symptoms & Autoregulation \\
\hline \multirow[t]{8}{*}{ Minor head-injury } & Sympathetic dysregulation \\
\hline & Electrocardiogram \\
\hline & Orthostatic \\
\hline & Postural tachycardia syndrome \\
\hline & Baroreflex \\
\hline & Baroreflex sensitivity \\
\hline & Heart rate variability \\
\hline & QT interval variability \\
\hline
\end{tabular}

classified as Class IV under AAN guideline criteria. What case studies and case series can shed light on are clinical or experimental observations that are notable and supportive of future research with more rigorous designs.

The samples represented in the case studies and case series identified by the literature search are diverse and range from athletes (La Fountaine, Toda, Testa, \& Bauman, 2014; Lagos, Thompson, \& Vaschillo, 2012; Middleton, Krabak, \& Coppel, 2010; Pellman, Viano, Casson, Arfken, \& Powell, 2004), to pediatric patients (Heyer et al., 2016; Middleton et al., 2010), and military personnel injured in IED blasts (Sams, LaBrie, Norris, Schauer, \& Frantz, 2012). ANS anomalies reported in these diverse samples alerts us to the possibility that ANS dysfunction can follow injury in a wide range of concussion subpopulations.

The studies sampled concussed participants at varying intervals post-injury. Some studies reported acute findings within the first week (La Fountaine et al., 2014; Pellman et al., 2004; Sams et al., 2012; Strebel, Lam, Matta, \& Newell, 1997; Vavilala et al., 2004), whereas other studies included patients beyond six months post-injury (Heyer et al., 2016; Mirow et al., 2016; Truong \& Ciuffreda, 2016b). This observation suggests that concussion can potentially impact the ANS in both acute and post-acute timeframes. Anomalies were identified using a wide variety of ANS evaluation techniques. The most common technique was heart rate variability analysis $(\mathrm{La}$ Fountaine et al., 2014; Lagos et al., 2012; Mirow 


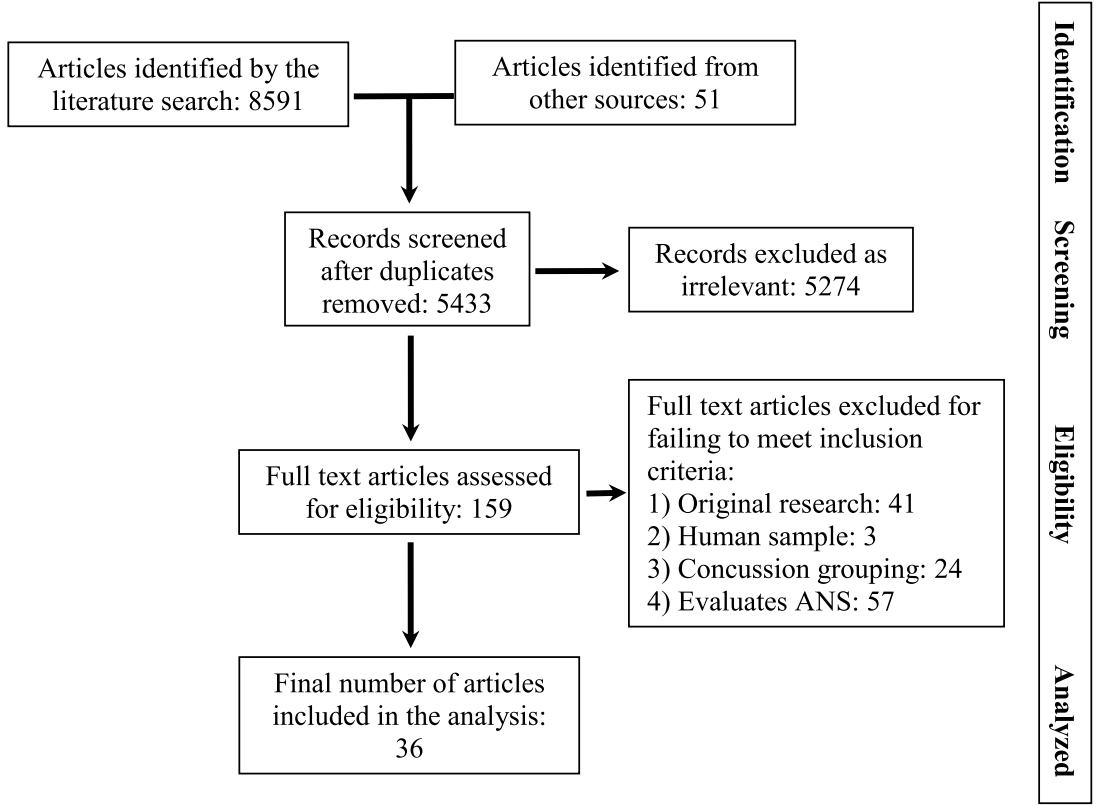

Fig. 1. Flow diagram documenting disposition of articles during the systematic review.

et al., 2016; G. Tan et al., 2009). Other techniques included Valsalva responses (Middleton et al., 2010), perfusion changes in relation to autonomic challenge (Strebel et al., 1997; Vavilala et al., 2004), tilt table testing (Heyer et al., 2016), pupil responsivity to light (Truong \& Ciuffreda, 2016b), and tracking syncopal and pre-syncopal symptoms (Pellman et al., 2004; Sams et al., 2012).

One of the most compelling case series sampled consecutive pediatric patients with concussion that had been referred for treatment at a pediatric headache clinic (Heyer et al., 2016). Patients reporting syncope or pre-syncopal symptoms prior to concussion, or syncope following concussion were excluded. The sample of 34 participants between the ages of 13 and 18 years completed head upright tilt table testing which evaluates the responsiveness of the baroreflex to postural changes. Patients were evaluated between 1 and 6 months post-injury. Syncope was observed in $29.5 \%$ of the sample and postural orthostatic tachycardia syndrome in $41.2 \%$ of the sample. Overall, $70.6 \%$ of the sample had anomalous tilt table test results.

\subsection{Insights from controlled studies of athletes}

Key characteristics of the controlled studies including athletes are summarized in Table 4. Ten sports concussion studies were included with a wide range of sports represented in primarily young adult samples. Some studies included data amenable to effect size calculation (Glass's delta was employed) and often multiple ANS variables were reported on. Due to the methodological diversity of design and measurement techniques between studies, pooling/combining data across studies using metaanalytic techniques was precluded. The magnitude of effect identified in the individual studies may be of interest to some readers and the effect size reported in each study is reported in Table 4. Where multiple variables were reported on relevant to ANS functioning, the variable with the strongest effect was included in the table. The strongest findings for each study on ANS variables ranged from $d=0.48$ (Hutchison et al., 2017) to $d=5.26$ (La Fountaine, Gossett, De Meersman, \& Bauman, 2011).

Patterns apparent in the data can be gleaned from perusal of Table 4 and include:

a) Autonomic anomalies were more apparent during conditions of physical challenge such as exercise or isometric handgrip conditions (apparent in 7 of 7 studies that included a physical demand condition (Abaji, Curnier, Moore, \& Ellemberg, 2016; Clark, Caudell-Stamper, Dailey, \& Divine, 2016; B. Gall, W. Parkhouse, \& D. Goodman, 2004a; B. Gall, W. S. Parkhouse, \& D. Goodman, 2004b; La Fountaine, Heffernan, Gossett, Bauman, \& De Meersman, 2009; 


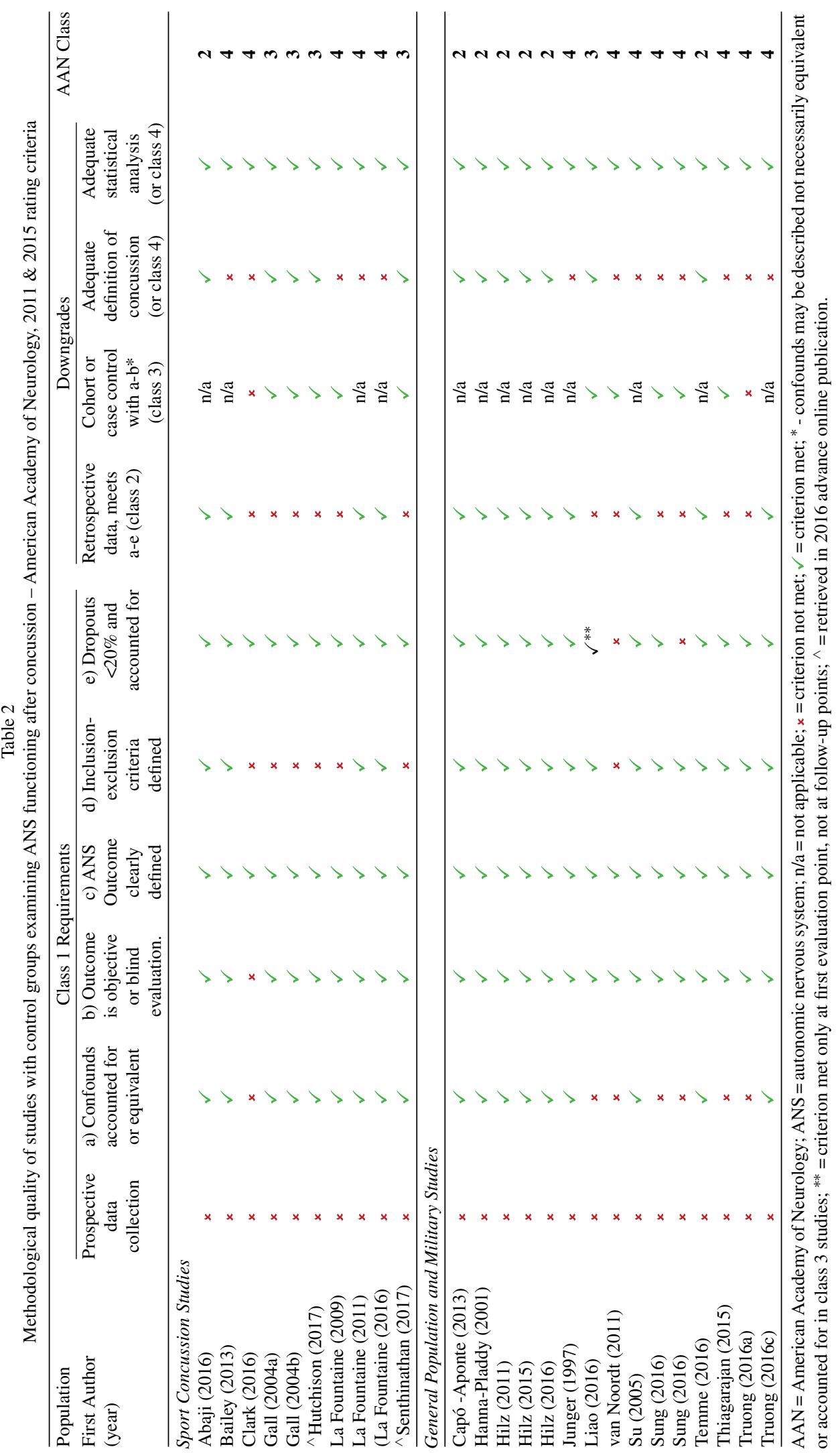




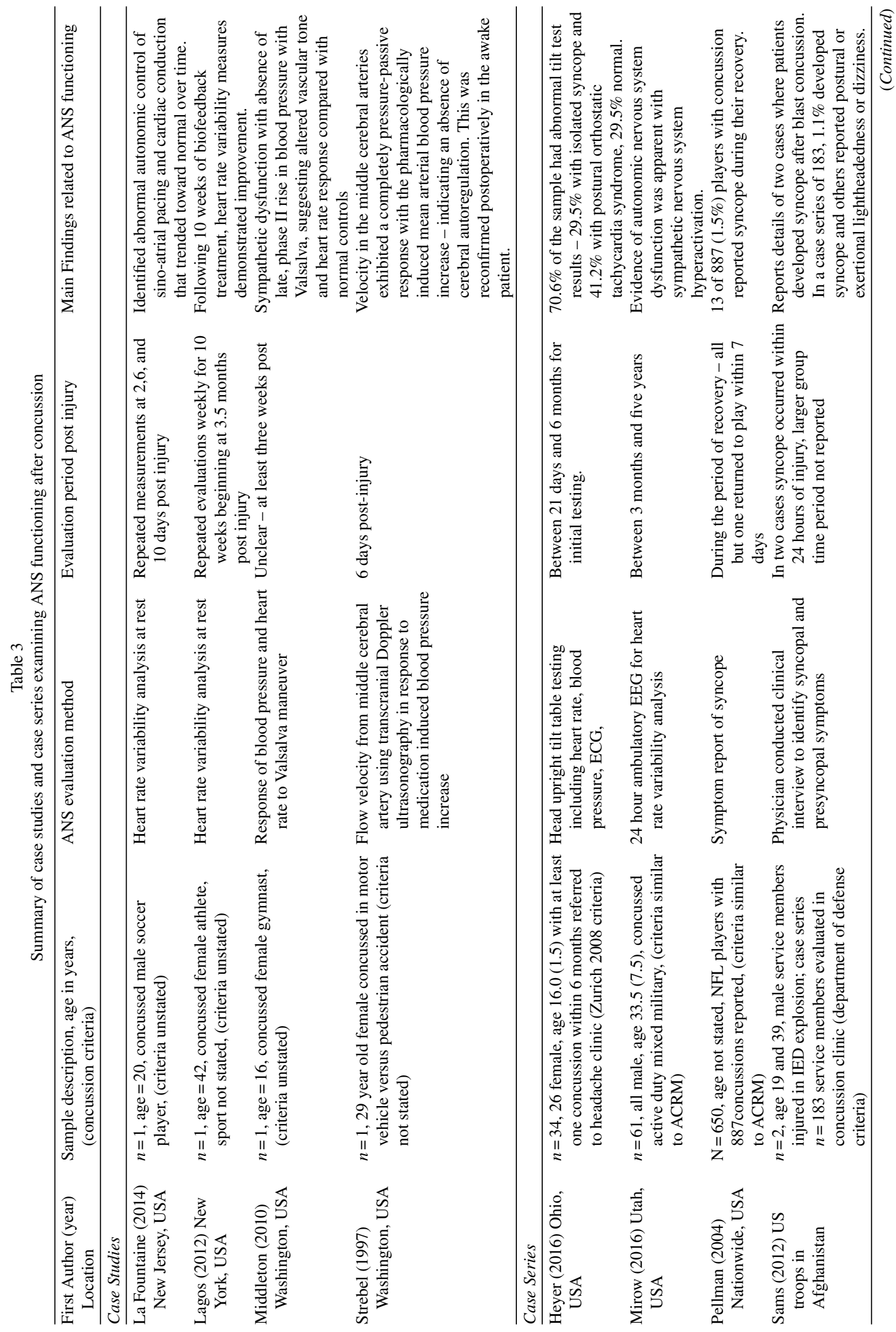


La Fountaine, Toda, Testa, \& Hill-Lombardi, 2016; Senthinathan, Mainwaring, \& Hutchison, 2017); they were also apparent in a study of simulated orthostatic challenge (Bailey et al., 2013). Anomalies at rest were found in 3 of 6 studies with a rest condition (Hutchison et al., 2017; La Fountaine et al., 2011; La Fountaine et al., 2016).

b) Anomalies were dominated by reduced parasympathetic nervous system involvement in concussed groups ( 5 of 5 studies (Abaji et al., 2016; Gall et al., 2004a; Hutchison et al., 2017; La Fountaine et al., 2011; Senthinathan et al., 2017)); effects on sympathetic nervous system (SNS) indicators were less consistent and included reduced SNS involvement (Gall et al., 2004a), lack of prominent sympathetic anomalies (Abaji et al., 2016; Hutchison et al., 2017), mixed effects (La Fountaine et al., 2016), or increased sympathetic tone (Senthinathan et al., 2017).

c) Anomalies in ANS functioning were apparent in athletes at varying timeframes post injury with evaluation ranging from within the first few days of injury (Gall et al., 2004a; La Fountaine et al., 2011; La Fountaine et al., 2016) to several months post injury (Abaji et al., 2016).

\subsection{Insights from controlled general population studies}

Key characteristics of the 15 controlled studies including general population samples are summarized in Table 4. Five studies sampled emergency department populations (Junger et al., 1997; Liao et al., 2016; Su et al., 2005; Sung, Chen, et al., 2016; Sung, Lee, et al., 2016), three sampled vision rehabilitation center patients (Thiagarajan \& Ciuffreda, 2015; Truong \& Ciuffreda, 2016a, 2016c), three studies sampled university students (Hanna-Pladdy, Berry, Bennett, Phillips, \& Gouvier, 2001; Hilz et al., 2015; van Noordt \& Good, 2011), one recruited from the community (Temme et al., 2016), and the remainder did not clearly report source of sample. In studies that included data amenable to effect size calculation, the strongest findings for each study on ANS variables ranged from $d=0.45$ (Sung, Chen, et al., 2016) to $d=10.0$ (Thiagarajan \& Ciuffreda, 2015); the strongest finding for each study is listed in Table 4. The methodological diversity of the studies and the samples evaluated precluded combination of data by meta-analytic/pooling methods. The methods for 


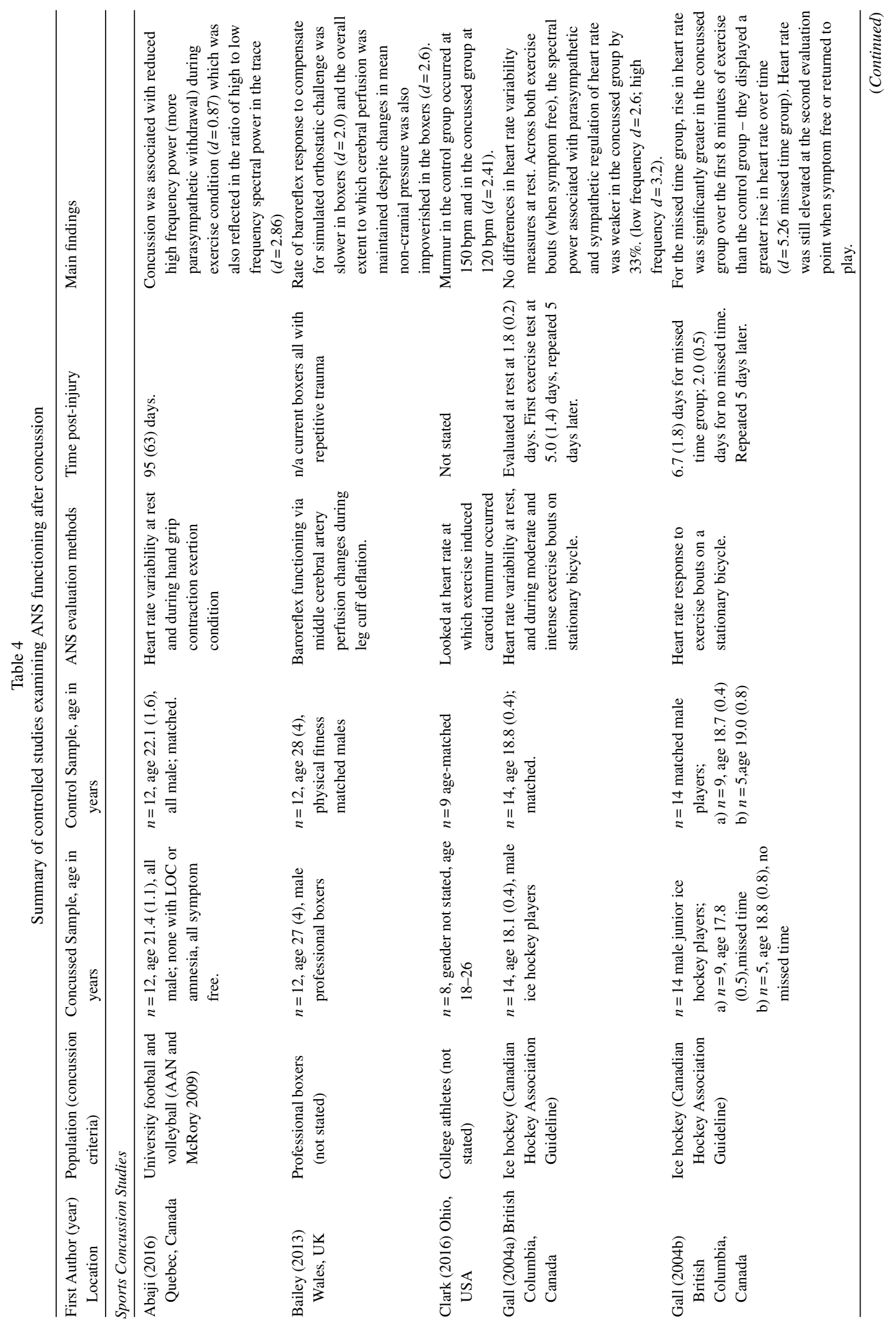




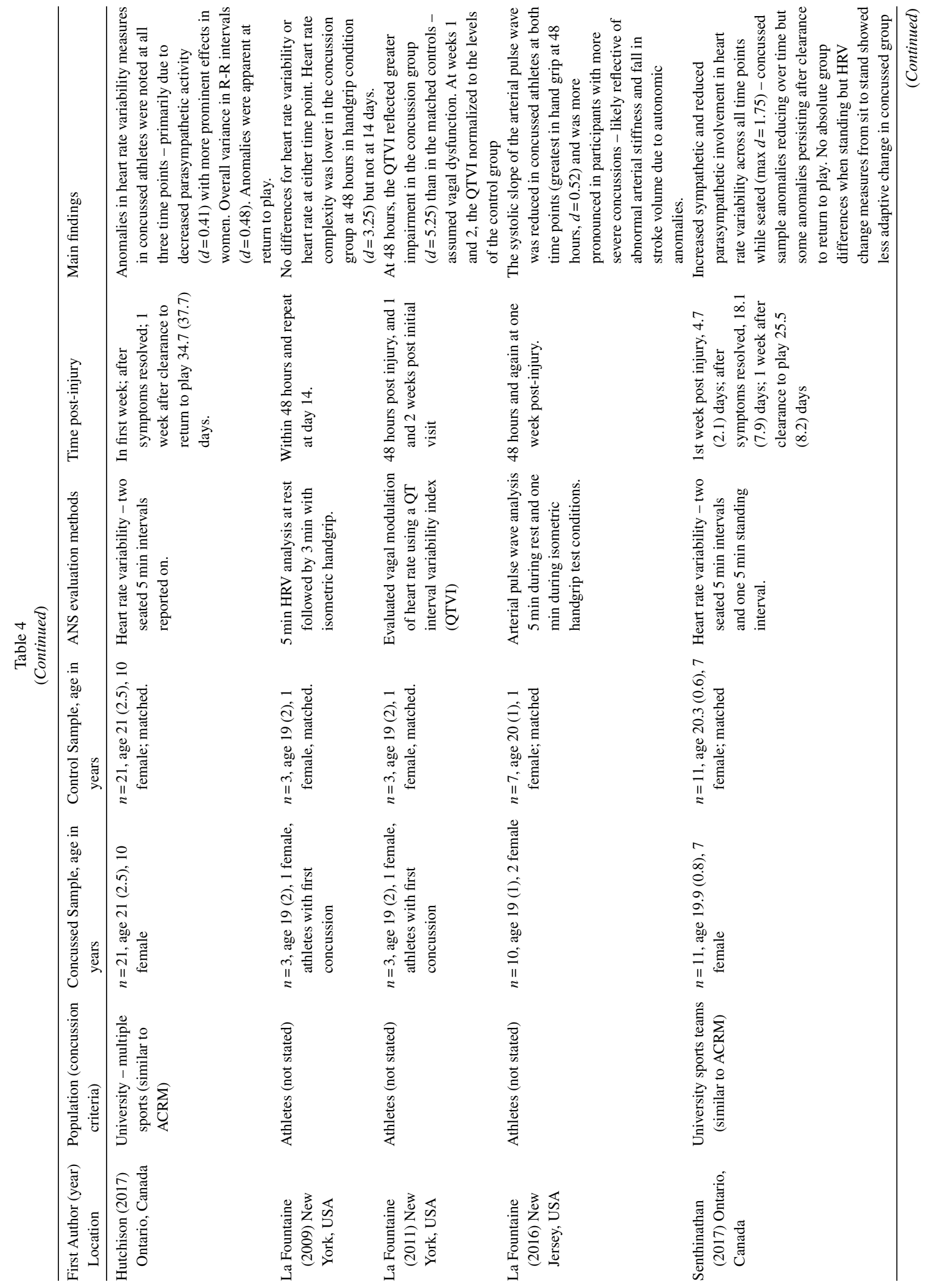




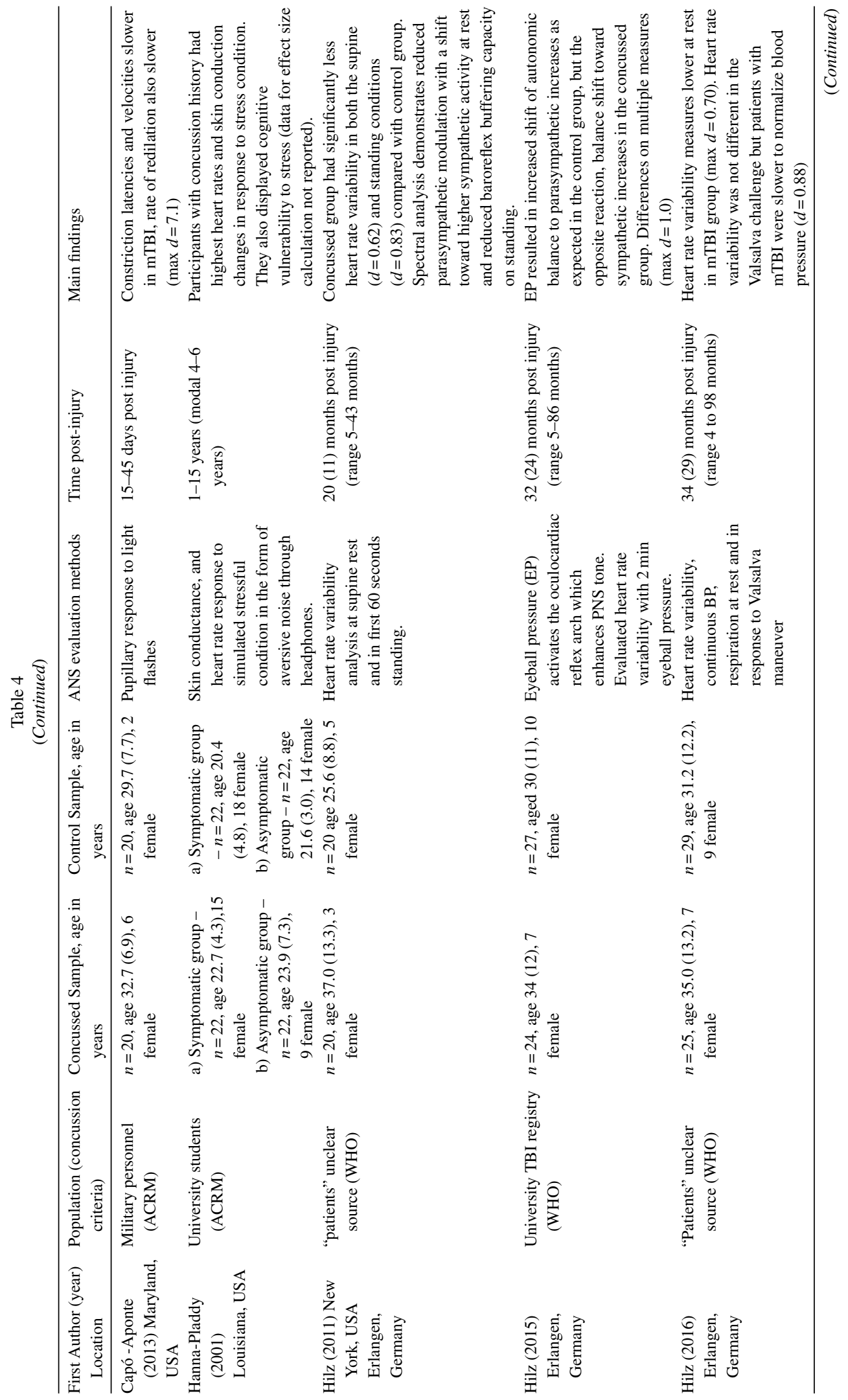




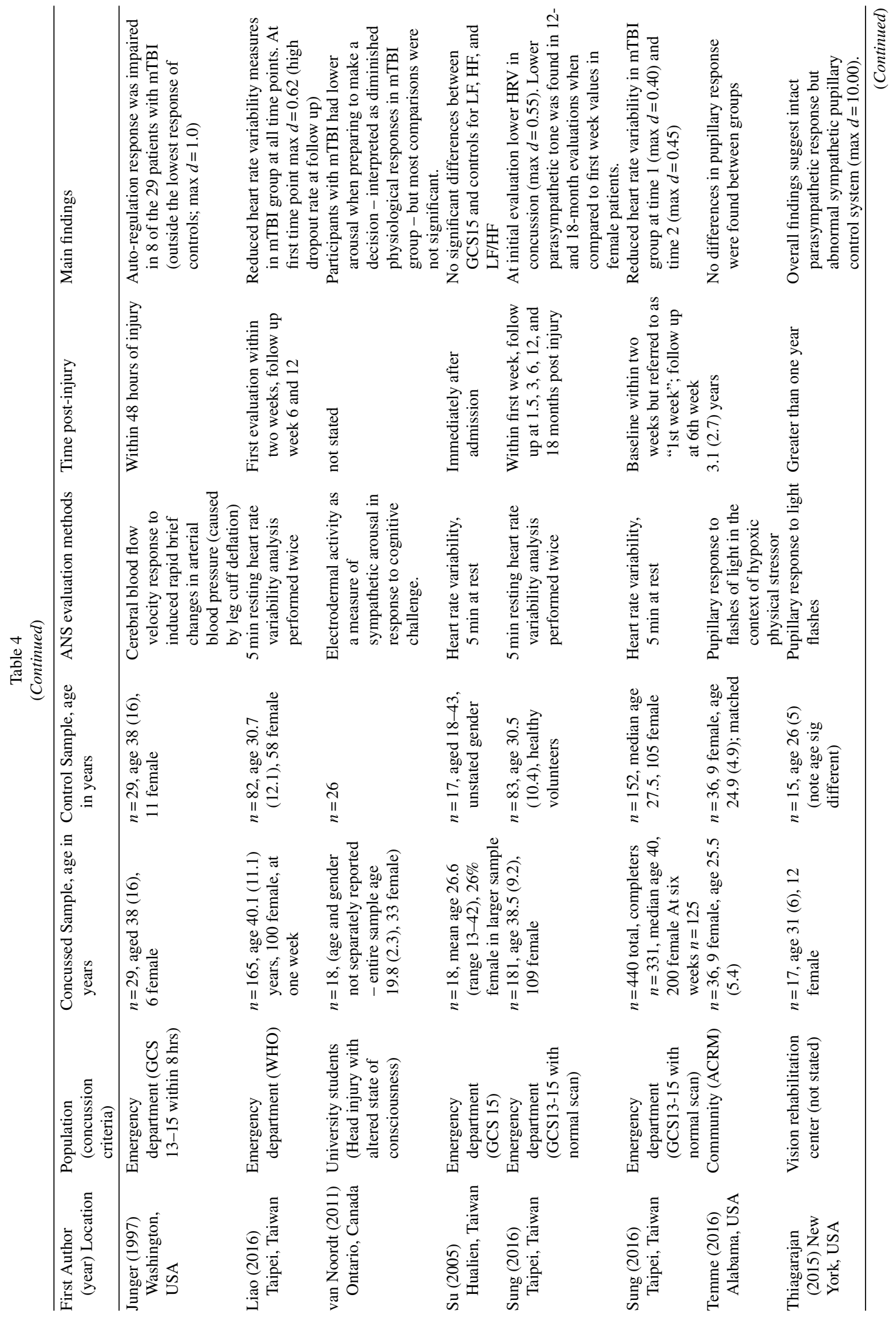


ANS evaluation were more diverse in the general population studies than the athlete studies but findings were consistent; concussed populations relative to control groups demonstrated:

a) Reduced parasympathetic involvement (8 of 13 studies (Capó-Aponte, Urosevich, Walsh, Temme, \& Tarbett, 2013; Hilz et al., 2011; Hilz et al., 2016; Liao et al., 2016; Sung, Chen, et al., 2016; Sung, Lee, et al., 2016; Thiagarajan \& Ciuffreda, 2015; Truong \& Ciuffreda, 2016a) with the remainder reporting no significant parasympathetic change).

b) Less efficient or suboptimal response to autonomic challenge (11 of 14 studies, (CapóAponte et al., 2013; Hanna-Pladdy et al., 2001; Hilz et al., 2011; Hilz et al., 2016; Junger et al., 1997; Liao et al., 2016; Sung, Chen, et al., 2016; Sung, Lee, et al., 2016; Thiagarajan \& Ciuffreda, 2015; Truong \& Ciuffreda, 2016a; van Noordt \& Good, 2011).

c) Impaired ANS functioning over a wide timeframe post-injury, ranging from the first 48 hours (Junger et al., 1997) to several years (Hanna-Pladdy et al., 2001; Hilz et al., 2015; Hilz et al., 2011; Hilz et al., 2016).

Two studies demonstrated notable sympathetic nervous system hypersensitivity (Hilz et al., 2015; Hilz et al., 2011), but as with sports concussion studies SNS anomalies were variable in both detection and direction. In one interesting study, university students with a remote concussion history several years earlier were evaluated for cognitive functioning and autonomic reaction to the environmental stressor of unpleasant noise via headphones (Hanna-Pladdy et al., 2001). Concussed students had larger increases in sympathetic nervous system responses and decreases in cognitive processing efficiency. These findings were more pronounced in students with concussion who also reported postconcussive symptoms at the time of the study.

\section{Conclusions}

This study was designed to answer the question: "Does concussion cause ANS anomalies?" Based on a systematic review that followed the protocols outlined by the AAN the following conclusion was reached: "It is 'likely' that concussion causes ANS anomalies." 
The mechanism of action between concussion and ANS dysfunction has yet to be fully elucidated. Potentially, ANS anomalies after concussion are the direct physiologic effect of damage to central and peripheral ANS structures. Some authors have proposed that structures in the region of the midbrain (where many central autonomic regulators reside) may be preferentially vulnerable to the impact of concussion (Jang \& Kwon, 2017; Ropper \& Gorson, 2007). Animal models of concussion suggest that brain stem anomalies after concussion can contribute to ANS dysregulation (Sinha et al., 2017). Peripheral ANS structures vulnerable to forces involved in concussion include the cervical sympathetic chain (SNS) and the vagus nerve and its branches (PNS) which pass through the cervical spine region. Damage to cervical spinal structures in injuries such as whiplash and cervical strain are known to correlate with ANS anomalies including dysfunction in the cervical sympathetic chain in some patients (Adeboye, Emerton, \& Hughes, 2000; Sterling, 2011). There is marked overlap between the symptoms of concussion and cervical strain/whiplash injuries and a growing body of research supports increased clinical attention to neck pathology in patients with concussion (Morin et al., 2016).

Some authors have found correlates between level of emotional distress after concussion and autonomic anomalies. It is unclear at this point to what extent the emotional impact of concussion reflects the physiologic impact of situational/physical/emotional stressors associated with the injury or direct physiologic impact of the injury to the emotional circuitry in the brain (X. Wang et al., 2017). It is also unclear to what extent circuitry associated with resilience, such as pain resilience might also be compromised (Leung et al., 2016). In one study included in the analysis (Liao et al., 2016), patients with mTBI had impaired autonomic functioning relative to controls, regardless of whether or not they reported high or low levels of anxiety; but those patients with mTBI with anxiety displayed more prominent ANS dysfunction on HRV analysis.

The relationship between concussion and the autonomic nervous system is relevant to the field for multiple reasons:

The relationship found between concussion and ANS anomalies is supportive of a paradigm shift in the field that supports including non-central nervous system factors in research and clinical models. The ANS and other body systems are involved in optimizing physiologic functioning to match the circumstances that the individual is facing. Only a partial understanding of concussion will emerge if the field continues to focus almost exclusively on its central nervous system effects. Important physiologic principles associated with dysregulation of the ANS, HPA axis, the immune system, and other body systems may result from a broader focus of research.

The relationship between concussion and ANS anomalies provides a plausible mechanism that accounts for the similarity of concussion symptoms with other medical conditions. Some of the research related to the similarity of concussion symptoms and the symptoms associated with other medical conditions was presented in the introduction to this paper. Because the data supports a likely relationship between ANS dysfunction and concussion that can persist over months and years post-injury, it should not be surprising that other medical conditions associated with ANS anomalies (chronic pain, orthostatic hypotension, chronic fatigue, anxiety, depression, whiplash, insomnia, etc.) have symptom overlap with concussion. We reiterate that ANS dysfunction is only one aspect of the neuropathology of concussion that has the potential to contribute to symptoms. Other variables such as mitochondrial dysfunction, micro-hemorrhages, axonal injury, neuroinflammatory responses, pituitary dysfunction, and other variables may also be active contributors to ongoing symptoms in some patients (Hadanny \& Efrati, 2016; Signoretti, Vagnozzi, Tavazzi, \& Lazzarino, 2010; Tanriverdi et al., 2010; Wofford et al., 2017). While likely not the only variable involved in persistent postconcussive complaints, the shared ANS pathology with other medical conditions clarifies why concussion does not produce a unique symptom profile.

\subsection{ANS informed concussion treatment}

The relationship between concussion and ANS anomalies can inform treatment decisions with patients presenting with postconcussive complaints. A more complete understanding of the physical impact of concussion can alert clinicians to a wider range of treatment possibilities.

In making treatment decisions, practitioners in the area of concussion are not armed with a solid foundation of evidence-based options founded in high quality randomized controlled trials. As noted in the AAN manual that formed the core methodology of this review, evidence in the form of randomized controlled trials is only one source of knowledge that 
clinicians use to make treatment decisions. Other factors include awareness of "neuroanatomic principles" and intuitive clinical "judgment." Increased awareness of the neuroanatomic principles of concussion in relationship to the ANS opens up opportunities for a wider range of plausible interventions and a rationale for streamlining treatment decisions. There are several ways in which incorporating an ANS framework into rehabilitation informs treatment.

a) Several authors have proposed that treatment modalities that directly target ANS imbalances may be useful in concussion populations. Among the modalities proposed is biofeedback training in various forms (Conder \& Conder, 2015; Jenkins, 2012; Lagos et al., 2012; Lagos, Thompson, \& Vaschillo, 2013; Tegeler et al., 2016; Thompson, Thompson, \& Reid-Chung, 2015). Noninvasive vagal nerve stimulation (Clancy et al., 2014; Kirsch \& Smith, 2000) is another potential direct ANS intervention, although it has not yet been explored in concussion populations.

b) It is also relevant that concussion does not always occur in patients who are in perfect physical condition. Patients may present with a number of physical conditions prior to their injury that place strain on the ANS. In addition to the direct effects of concussion on ANS functioning, associated injury factors such as pain may further encumber optimal ANS functioning. Consider a 50-year-old male who is concussed in a fall from a ladder. He has a pre-injury history of depressed mood and chronic workplace stress; following the concussion he experiences insomnia, chronic pain, and deconditioning due to a leg fracture associated with the fall. The clinician is working with a patient who has at least five variables negatively impacting ANS functioning in addition to concussion. It is our clinical experience that a holistic approach that takes all these variables into account in the treatment planning is much more likely to lead to resolution of postconcussive complaints than one that is narrowly focused on any one of these variables.

c) An awareness that ANS dysfunction and associated persistent cerebral perfusion changes may be among the prominent contributors to postconcussive complaints opens up a range of therapeutic opportunities for supporting ANS balance in the injured patient. Clinicians can provide individually timed sequential education regarding the many behavioral variables that can empower patients to stabilize the ANS and reduce symptoms. Opportunities for intervention include:

- Cognitive behavioral therapy for mood disorders, post-traumatic symptoms, anxiety symptoms, and insomnia (Bryant, 2011; Ruff, Riechers, Wang, Piero, \& Ruff, 2012).

- Efforts to reduce unpredictability and chronic stress by establishing a sustainable daily routine, liaising with employers or school personnel, or efforts to reduce relationship/family distress and role ambiguity in the face of injury (Lennartsson, Jonsdottir, \& Sjors, 2016; Thayer, Ahs, Fredrikson, Sollers, \& Wager, 2012).

- Education regarding nutrition variables that impact the ANS (Buchhorn, Hauk, Meint, \& Willaschek, 2016; Dippacher, Willaschek, \& Buchhorn, 2014; Kitamura, Torii, Uneyama, \& Niijima, 2010; Kopp, 2009; Luyer, Habes, van Hak, \& Buurman, 2011).

- Graded exercise programs (Gagnon, Galli, Friedman, Grilli, \& Iverson, 2009; J. Leddy et al., 2016; Sanudo, Carrasco, de Hoyo, Figueroa, \& Saxton, 2015; C. O. Tan, Meehan, Iverson, \& Taylor, 2014)

- Relaxation and meditation protocols in their various forms (Charalambous, Giannakopoulou, Bozas, \& Paikousis, 2015; Jerath, Edry, Barnes, \& Jerath, 2006; Pal, Velkumary, \& Madanmohan, 2004; Tang, Holzel, \& Posner, 2015)

- Positive event scheduling (Kop et al., 2011; McCraty, Atkinson, Tiller, Rein, \& Watkins, 1995)

- Treatment of cervical strain, mobility, and pain issues (Marshall, Vernon, Leddy, \& Baldwin, 2015; Morikawa et al., 2017; Morin et al., 2016; Ye, Lee, Lin, \& Chuang, 2017)

These types of intervention have not been validated for patients with concussion in high quality randomized controlled trials (no AAN Grade I or II trials) to date. Patients can be informed of this and educated that the individually tailored application in concussion rehabilitation for persistent symptoms is indicated given our awareness of "neuroanatomic principles" associated with concussion and the impact of such variables on ANS optimization. 
Detailed discussion of how these techniques can be applied to patients with concussion and how they benefit autonomic functioning is beyond the scope of this paper. This section on treatment is intended to briefly highlight some promising opportunities for concussion rehabilitation that are informed in part by an awareness of the "likely" relationship between concussion and autonomic functioning.

d) Prescribing providers should be cautious in prescribing medications that have the potential to further undermine ANS functioning in patients with concussion. For patients whose response to ANS stabilizing behavioral interventions is suboptimal, or those who prefer a non-behavioral treatment approach, medication intervention in ANS functioning may be a fruitful option. Many patients may have pre-existing prescriptions for ANS impacting medications that may need to be re-considered in the face of their injury. The classes of medication that have the potential to deleteriously impact ANS functioning are many and because the body is a unitary system there may be few medications that do not impact the ANS (Pleuvry, 2007). Providers should consider the potential ANS impact of medications as part of their decision-making for treatment interventions. Classes of medication where caution is indicated include SNRI and (to a lesser extent) SSRI medications, tricyclic antidepressants, antihistamines, antipsychotics, and beta blockers (Becker, 2012; Koschke et al., 2009).

\subsection{Limitations of the systematic review}

The present systematic review is limited by a number of external and internal variables. External variables such as publication of positive results biases, limited understanding of which measures are most sensitive to ANS anomalies in concussion research, and very few standardized assessment procedures limit the quantity and quality of data available for incorporation into a systematic review.

Internal variables that limit the quality of this review include the inherent subjectivity associated with development of the study question, study identification and selection decisions, and risk of bias evaluation processes. We sought to limit subjectivity in our processes by rigidly following published PRISMA, AAN, and Institute of Medicine guidelines. Clearly defining the inclusion criteria, and operationalizing bias evaluation criteria was also employed to reduce subjectivity. Creation of independent, two party, data extraction at the screening and eligibility stages of the evaluation was also employed to reduce subjectivity. Even so, ratings reported in this paper reflect the subjective opinions of the authors to some extent. For example, our decision to judge concussion definitions that relied solely on Glasgow Coma Scale score as inadequate may be considered too stringent by some; our decision to include multiple commonly used concussion definitions (ACRM, WHO, DOD) may be considered too liberal by others. However, where appropriate, we have attempted to be explicit regarding our decision making to facilitate the reader's interpretation of the results.

It is also possible, if not probable, that we did not identify every study relevant to our PICOS question in the timeframe considered (articles available through the end of 2016). This would reflect a weakness in the search strategy and identification stage. To limit the risk of under-identification, we employed the support of a medical librarian, conducted searches on multiple databases, and crosschecked our results and refined the search terms using key articles in the field that were identified in a preliminary search. We also included broad search headings to compensate for the observation that many concussion studies are indexed in databases under broader categories of brain injury. This resulted in a large number of titles and abstracts to review (over 5,000), and while this was labor intensive it was considered warranted to minimize the risk of excluding relevant articles by employing more narrow terms.

Many systematic reviews identify a principle summary measure for the outcome of interest (e.g. relative risk of mortality, or mean difference in viral load in response to a treatment (Liberati et al., 2009). This was not possible in the current study as measures of ANS functioning employed in concussion research are diverse. There were no two studies that employed an identical ANS outcome evaluation procedure. This precluded both meta-analytic combination of data across studies and also defining a principle/primary summary measure of ANS functioning. The lack of specificity in outcome measure designation reflects the lack of homogeneity in the available research and is reflected in the broad research question and nonspecific conclusions that are drawn. We can conclude that concussion "likely" causes ANS anomalies but cannot specify with systematic precision what outcomes are most affected or the magnitude of those effects. 


\subsection{Recommendations for future research}

Many of the articles included in the final analysis of this paper would have warranted a higher AAN grading if they had included a) appropriate inclusion and exclusion criteria, and b) a clear definition of how concussion groups were diagnosed and what criteria was employed to define concussion. Incorporating these fundamental design factors would appear to place minimal extra burden or expense on future research studies. Seven of the 25 studies included in the analysis did not include inclusion-exclusion criteria (automatic downgrade to class 3 or below), and 13 of 25 had inadequate or even absent description of how concussion was determined (automatic downgrade to class 4, see Table 2). No Class I studies were identified in the review, the primary reason for this being the absence of studies that included prospective (baseline) data collection. In clarifying causation in naturalistic human samples, well-designed prospective cohort studies are an optimal approach.

The articles reviewed presented a range of innovative assessment tools that can be incorporated into future research - many of these were non-invasive, placed minimal time demands on participants, and used equipment that is only of modest cost (compared to other forms of research in the area such as fMRI). These observations suggest that this area of research is relatively practical and affordable in the context of the field as a whole.

Significant findings were apparent even in studies with very small sample sizes, which supports the potential benefit of research investment into larger studies. Clearly, prospective studies (with baseline data collection), larger sample sizes, multimodal evaluation (ANS, CNS, cognitive, behavioral variables etcetera), serial assessment over time and at varying intervals post-injury, and incorporating ANS variables into treatment efficacy studies would enhance the quality of future research.

\subsection{Executive summary}

Concussion "likely" causes anomalies in ANS functioning. An awareness of this relationship not only increases our awareness of the physical impact of concussion, but it also further legitimizes the experience of patients with persistent symptoms, partially explains the overlap of concussion symptoms with those of many other medical conditions, presents opportunities for a potentially fruitful area of concussion research, and has the potential to powerfully inform treatment decisions. We plan to publish a companion article to this systematic review that outlines a stepwise concussion rehabilitation framework that is informed by the ANS principles included in this paper.

\section{Conflict of interest}

All of the authors declare that they have no conflict of interest. Dr. Merkley was granted research time through the Barrow Neurological Institute. Otherwise, no sources of funding were employed at any stage in the development of this paper.

\section{References}

Abaji, J. P., Curnier, D., Moore, R. D., \& Ellemberg, D. (2016). Persisting effects of concussion on heart rate variability during physical exertion. J Neurotrauma, 33(9), 811-817. doi:10.1089/neu.2015.3989

Adeboye, K. A., Emerton, D. G., \& Hughes, T. (2000). Cervical sympathetic chain dysfunction after whiplash injury. $J R$ Soc Med, 93(7), 378-379. doi:10.1177/014107680009300713

Ahman, S., Saveman, B. I., Styrke, J., Bjornstig, U., \& Stalnacke, B. M. (2013). Long-term follow-up of patients with mild traumatic brain injury: A mixed-method study. J Rehabil Med, 45(8), 758-764. doi:10.2340/16501977-1182

Arnold, A. C., Haman, K., Garland, E. M., Raj, V., Dupont, W. D., Biaggioni, I., . . \& Raj, S. R. (2015). Cognitive dysfunction in postural tachycardia syndrome. Clin Sci (Lond), 128(1), 39-45. doi:10.1042/CS20140251

Bailey, D. M., Jones, D. W., Sinnott, A., Brugniaux, J. V., New, K. J., Hodson, D., . . \& A Ainslie, P. N. (2013). Impaired cerebral haemodynamic function associated with chronic traumatic brain injury in professional boxers. Clin Sci (Lond), 124(3), 177-189. doi:10.1042/CS20120259

Barlow, K. M., Marcil, L. D., Dewey, D., Carlson, H. L., MacMaster, F. P., Brooks, B. L., \& Lebel, R. M. (2017). Cerebral perfusion changes in post-concussion syndrome: A prospective controlled cohort study. J Neurotrauma, 34(5), 996-1004. doi:10.1089/neu.2016.4634

Barrett, K., Ward, A. B., Boughey, A., Jones, M., \& Mychalkiw, W. (1994). Sequelae of minor head injury: The natural history of post-concussive symptoms and their relationship to loss of consciousness and follow-up. J Accid Emerg Med, 11(2), 79-84.

Bartnik-Olson, B. L., Holshouser, B., Wang, H., Grube, M., Tong, K., Wong, V., \& Ashwal, S. (2014). Impaired neurovascular unit function contributes to persistent symptoms after concussion: A pilot study. J Neurotrauma, 31(17), 1497-1506. doi:10.1089/neu.2013.3213

Bassett, D. (2016). A literature review of heart rate variability in depressive and bipolar disorders. Aust N Z J Psychiatry, 50(6), 511-519. doi:10.1177/0004867415622689

Basta, M., Chrousos, G. P., Vela-Bueno, A., \& Vgontzas, A. N. (2007). Chronic insomnia and stress system. Sleep Med Clin, 2(2), 279-291. doi:10.1016/j.jsmc.2007.04.002 
Bazarian, J. J., McClung, J., Shah, M. N., Cheng, Y. T., Flesher, W., \& Kraus, J. (2005). Mild traumatic brain injury in the United States, 1998-2000. Brain Inj, 19(2), 85-91.

Becker, D. E. (2012). Basic and clinical pharmacology of autonomic drugs. Anesthesia Progress, 59(4), 159-169.

Beissner, F., \& Baudrexel, S. (2014). Investigating the human brainstem with structural and functional MRI. Front Hum Neurosci, 8, 116. doi:10.3389/fnhum.2014.00116

Bellerose, J., Bernier, A., Beaudoin, C., Gravel, J., \& Beauchamp, M. H. (2017). Long-term brain-injury-specific effects following preschool mild TBI: A study of theory of mind. Neuropsychology, 31(3), 229-241. doi:10.1037/neu0000341

Benarroch, E. E. (1993). The central autonomic network: Functional organization, dysfunction, and perspective. Mayo Clin Proc, 68(10), 988-1001.

Bigler, E. D., Abildskov, T. J., Goodrich-Hunsaker, N. J., Black, G., Christensen, Z. P., Huff, T., ...\& Max, J. E. (2016). Structural neuroimaging findings in mild traumatic brain injury. Sports Med Arthrosc, 24(3), e42-52. doi:10.1097/JSA.0000000000000119

Bishop, S. A., \& Neary, J. P. (2015). Autonomic, cerebrovascular and mild traumatic brain injury physiology:linkages and future applications. Curr Res Concussion, 2(2), 49-58.

Bonne, O., Gilboa, A., Louzoun, Y., Kempf-Sherf, O., Katz, M., Fishman, Y., ...\& Lerer, B. (2003). Cerebral blood flow in chronic symptomatic mild traumatic brain injury. Psychiatry Res, 124(3), 141-152.

Brudey, C., Park, J., Wiaderkiewicz, J., Kobayashi, I., Mellman, T. A., \& Marvar, P. J. (2015). Autonomic and inflammatory consequences of posttraumatic stress disorder and the link to cardiovascular disease. Am J Physiol Regul Integr Comp Physiol, 309(4), R315-321. doi:10.1152/ajpregu.00343.2014

Bryant, R. (2011). Post-traumatic stress disorder vs traumatic brain injury. Dialogues Clin Neurosci, 13(3), 251-262.

Buchhorn, R., Hauk, F., Meint, S., \& Willaschek, C. (2016). The impact of nutrition on the autonomic nervous system. Int $J$ Food Nutr Sci, 3(3), 1-16.

Capó-Aponte, J. E., Urosevich, T. G., Walsh, D. V., Temme, L. A., \& Tarbett, A. K. (2013). Pupillary light reflex as an objective biomarker for early identification of blast-induced mTBI. $J$ Spine, S4. doi:10.4172/2165-7939.S4-004

Carroll, L. J., Cassidy, J. D., Peloso, P. M., Borg, J., von Holst, H., Holm, L., Paniak C., Pépin M., \& WHO Collaborating Centre Task Force on Mild Traumatic Brain Injury (2004). Prognosis for mild traumatic brain injury: Results of the WHO Collaborating Centre Task Force on Mild Traumatic Brain Injury. $J$ Rehabil Med(43 Suppl), 84-105.

Chan, R. (2005). How severe should symptoms be before someone is said to be suffering from post-concussion syndrome? An exploratory study with self-reported checklist using Rasch analysis. Brain Inj, 19(13), 1117-1124. doi:10.1080/026990500150088

Charalambous, A., Giannakopoulou, M., Bozas, E., \& Paikousis, L. (2015). A randomized controlled trial for the effectiveness of progressive muscle relaxation and guided imagery as anxiety reducing interventions in breast and prostate cancer patients undergoing chemotherapy. Evid Based Complement Alternat Med, 2015, 270876. doi:10.1155/2015/270876

Chrousos, G. P. (2009). Stress and disorders of the stress system. Nat Rev Endocrinol, 5(7), 374-381. doi:10.1038/nrendo.2009.106
Churchill, N., Hutchison, M., Richards, D., Leung, G., Graham, S., \& Schweizer, T. A. (2017). Brain structure and function associated with a history of sport concussion: A multi-modal magnetic resonance imaging study. J Neurotrauma, 34(4), 765771. doi:10.1089/neu.2016.4531

Churchill, N. W., Hutchison, M. G., Richards, D., Leung, G., Graham, S. J., \& Schweizer, T. A. (2017). The first week after concussion: Blood flow, brain function and white matter microstructure. Neuroimage Clin, 14, 480-489. doi:10.1016/j.nicl.2017.02.015

Clancy, J. A., Mary, D. A., Witte, K. K., Greenwood, J. P., Deuchars, S. A., \& Deuchars, J. (2014). Non-invasive vagus nerve stimulation in healthy humans reduces sympathetic nerve activity. Brain Stimul, 7(6), 871-877. doi:10.1016/j.brs.2014. 07.031

Clark, J. F., Caudell-Stamper, D. N., Dailey, S. W., \& Divine, J. G. (2016). Can a transient exertion-related carotid (TERC) murmur heard during a symptom-limited exercise test be used as a means for managing sports concussion? Med Hypotheses, 93, 11-15. doi:10.1016/j.mehy.2016.05.003

Clausen, M., Pendergast, D. R., Willer, B., \& Leddy, J. (2016). Cerebral blood flow during treadmill exercise is a marker of physiological postconcussion syndrome in female athletes. J Head Trauma Rehabil, 31(3), 215-224. doi:10.1097/HTR.0000000000000145

Coghill, R. C., Sang, C. N., Berman, K. F., Bennett, G. J., \& Iadarola, M. J. (1998). Global cerebral blood flow decreases during pain. J Cereb Blood Flow Metab, 18(2), 141-147. doi:10.1097/00004647-199802000-00003

Conder, R., \& Conder, A. A. (2015). Neuropsychological and psychological rehabilitation interventions in refractory sportrelated post-concussive syndrome. Brain Inj, 29(2), 249-262. doi:10.3109/02699052.2014.965209

Convertino, V. A., Doerr, D. F., Eckberg, D. L., Fritsch, J. M., \& Vernikos-Danellis, J. (1990). Head-down bed rest impairs vagal baroreflex responses and provokes orthostatic hypotension. J Appl Physiol (1985), 68(4), 1458-1464.

Cottingham, M. E., \& Boone, K. B. (2014). Malingering in mild traumatic brain injury. In M. Sherer \& A.M. Sander (Eds.), Handbook on the Neuropsychology of Traumatic Brain Injury. New York: Springer-Verlag.

Coupe, M., Fortrat, J. O., Larina, I., Gauquelin-Koch, G., Gharib, C., \& Custaud, M. A. (2009). Cardiovascular deconditioning: From autonomic nervous system to microvascular dysfunctions. Respir Physiol Neurobiol, 169(Suppl 1), S10-12. doi:10.1016/j.resp.2009.04.009

D’Souza M, M., Trivedi, R., Singh, K., Grover, H., Choudhury, A., Kaur, P., ...\& Tripathi, R. P. (2015). Traumatic brain injury and the post-concussion syndrome: A diffusion tensor tractography study. Indian J Radiol Imaging, 25(4), 404-414. doi:10.4103/0971-3026.169445

de Guise, E., Lepage, J. F., Tinawi, S., LeBlanc, J., Dagher, J., Lamoureux, J., \& Feyz, M. (2010). Comprehensive clinical picture of patients with complicated vs uncomplicated mild traumatic brain injury. Clin Neuropsychol, 24(7), 1113-1130. doi:10.1080/13854046.2010.506199

de Koning, M. E., Scheenen, M. E., van der Horn, H. J., Hageman, G., Roks, G., Spikman, J. M., \& van der Naalt, J. (2017). Non-hospitalized patients with mild traumatic brain injury: The forgotten minority. J Neurotrauma, 34(1), 257-261. doi:10.1089/neu.2015.4377 
Dean, P. J., Sato, J. R., Vieira, G., McNamara, A., \& Sterr, A. (2015). Long-term structural changes after mTBI and their relation to post-concussion symptoms. Brain Inj, 1-8. doi:10.3109/02699052.2015.1035334

Dippacher, S., Willaschek, C., \& Buchhorn, R. (2014). Different nutritional states and autonomic imbalance in childhood. Eur J Clin Nutr, 68(11), 1271-1273. doi:10.1038/ejcn.2014.198

Donnell, A. J., Kim, M. S., Silva, M. A., \& Vanderploeg, R. D. (2012). Incidence of postconcussion symptoms in psychiatric diagnostic groups, mild traumatic brain injury, and comorbid conditions. Clin Neuropsychol, 26(7), 1092-1101. doi:10.1080/13854046.2012.713984

Duschek, S., Muck, I., \& Reyes Del Paso, G. A. (2007). Relationship between baroreceptor cardiac reflex sensitivity and pain experience in normotensive individuals. Int J Psychophysiol, 65(3), 193-200. doi:10.1016/j.ijpsycho.2007.03.012

Duschek, S., Werner, N. S., \& Reyes Del Paso, G. A. (2013). The behavioral impact of baroreflex function: A review. Psychophysiology, 50(12), 1183-1193. doi:10.1111/psyp.12136

Elbin, R. J., Knox, J., Kegel, N., Schatz, P., Lowder, H. B., French, J., .. \& \& Kontos, A. P. (2016). Assessing symptoms in adolescents following sport-related concussion: A comparison of four different approaches. Appl Neuropsychol Child, 5(4), 294-302. doi:10.1080/21622965.2015.1077334

Elenkov, I. J., Wilder, R. L., Chrousos, G. P., \& Vizi, E. S. (2000). The sympathetic nerve-an integrative interface between two supersystems: The brain and the immune system. Pharmacol Rev, 52(4), 595-638.

Ellis, M. J., Ryner, L. N., Sobczyk, O., Fierstra, J., Mikulis, D. J., Fisher, J. A., . . \& Mutch, W. A. (2016). Neuroimaging assessment of cerebrovascular reactivity in concussion: Current concepts, methodological considerations, and review of the literature. Front Neurol, 7, 61. doi:10.3389/fneur.2016.00061

Farina, B., Dittoni, S., Colicchio, S., Testani, E., Losurdo, A., Gnoni, V., ...\& Della Marca, G. (2014). Heart rate and heart rate variability modification in chronic insomnia patients. Behav Sleep Med, 12(4), 290-306. doi:10.1080/15402002.2013.801346

Fazalbhoy, A., Birznieks, I., \& Macefield, V. G. (2014). Consistent interindividual increases or decreases in muscle sympathetic nerve activity during experimental muscle pain. Exp Brain Res, 232(4), 1309-1315. doi:10.1007/s00221-014-3847-7

Feigin, V. L., Theadom, A., Barker-Collo, S., Starkey, N. J., McPherson, K., Kahan, M., ...\& Group, B. S. (2013). Incidence of traumatic brain injury in New Zealand: A population-based study. Lancet Neurol, 12(1), 53-64. doi:10.1016/S1474-4422(12)70262-4

Ferguson, R. J., Mittenberg, W., Barone, D. F., \& Schneider, B. (1999). Postconcussion syndrome following sports-related head injury: Expectation as etiology. Neuropsychology, 13(4), 582-589.

Folino, A. F. (2007). Cerebral autoregulation and syncope. Prog Cardiovasc Dis, 50(1), 49-80. doi:10.1016/j.pcad.2007.01.001

Fourtassi, M., Hajjioui, A., Ouahabi, A. E., Benmassaoud, H., Hajjaj-Hassouni, N., \& Khamlichi, A. E. (2011). Long term outcome following mild traumatic brain injury in Moroccan patients. Clin Neurol Neurosurg, 113(9), 716-720. doi:10.1016/j.clineuro.2011.07.010

Fredrikson, M., Fischer, H., \& Wik, G. (1997). Cerebral blood flow during anxiety provocation. J Clin Psychiatry, 58(Suppl 16), $16-21$.
Friedman, B. H., \& Thayer, J. F. (1998). Autonomic balance revisited: Panic anxiety and heart rate variability. J Psychosom Res, 44(1), 133-151.

Gagnon, I., Galli, C., Friedman, D., Grilli, L., \& Iverson, G. L. (2009). Active rehabilitation for children who are slow to recover following sport-related concussion. Brain Inj, 23(12), 956-964. doi:10.3109/02699050903373477

Gall, B., Parkhouse, W., \& Goodman, D. (2004a). Heart rate variability of recently concussed athletes at rest and exercise. Med Sci Sports Exerc, 36(8), 1269-1274.

Gall, B., Parkhouse, W. S., \& Goodman, D. (2004b). Exercise following a sport induced concussion. Br J Sports Med, 38(6), 773-777. doi:10.1136/bjsm.2003.009530

Garden, N., Sullivan, K. A., \& Lange, R. T. (2010). The relationship between personality characteristics and postconcussion symptoms in a nonclinical sample. Neuropsychology, 24(2), 168-175. doi:10.1037/a0017431

Gardner, A. J., Tan, C. O., Ainslie, P. N., van Donkelaar, P., Stanwell, P., Levi, C. R., \& Iverson, G. L. (2015). Cerebrovascular reactivity assessed by transcranial Doppler ultrasound in sportrelated concussion: A systematic review. Br J Sports Med, 49(16), 1050-1055. doi:10.1136/bjsports-2014-093901

Garland, E. M., Celedonio, J. E., \& Raj, S. R. (2015). Postural tachycardia syndrome: Beyond orthostatic intolerance. Curr Neurol Neurosci Rep, 15(9), 60. doi:10.1007/s11910015-0583-8

Gasquoine, P. G. (2000). Postconcussional symptoms in chronic back pain. Appl Neuropsychol, 7(2), 83-89. doi:10.1207/S15324826AN0702_3

Gilkey, S. J., Ramadan, N. M., Aurora, T. K., \& Welch, K. M. (1997). Cerebral blood flow in chronic posttraumatic headache. Headache, 37(9), 583-587.

Giza, C. C., \& Hovda, D. A. (2014). The new neurometabolic cascade of concussion. Neurosurgery, 75(Suppl 4), S24-33. doi:10.1227/NEU.0000000000000505

Goadsby, P. J. (2004). Cerebral circulation - Autonomic influences. In D. Robertson (Ed.), Primer on the autonomic nervous system. London: Elsevier Academic Press.

Goldstein, B., Toweill, D., Lai, S., Sonnenthal, K., \& Kimberly, B. (1998). Uncoupling of the autonomic and cardiovascular systems in acute brain injury. Am J Physiol, 275(4 Pt 2), R1287-1292.

Gururaj, G. (2002). Epidemiology of traumatic brain injuries: Indian scenario. Neurol Res, 24(1), 24-28. doi:10.1179/ 016164102101199503

Hadanny, A., \& Efrati, S. (2016). Treatment of persistent postconcussion syndrome due to mild traumatic brain injury: Current status and future directions. Expert Rev Neurother, 16(8), 875-887. doi:10.1080/14737175.2016.1205487

Hallman, D. M., \& Lyskov, E. (2012). Autonomic regulation, physical activity and perceived stress in subjects with musculoskeletal pain: 24-hour ambulatory monitoring. Int J Psychophysiol, 86(3), 276-282. doi:10.1016/j.ijpsycho.2012.09.017

Hanna-Pladdy, B., Berry, Z. M., Bennett, T., Phillips, H. L., \& Gouvier, W. D. (2001). Stress as a diagnostic challenge for postconcussive symptoms: Sequelae of mild traumatic brain injury or physiological stress response. Clin Neuropsychol, 15(3), 289-304. doi:10.1076/clin.15.3.289.10272

Heart rate variability: Standards of measurement, physiological interpretation and clinical use. Task Force of the European Society of Cardiology and the North American Society of 
Pacing and Electrophysiology. (1996). Circulation, 93(5), 1043-1065.

Heitger, M. H., Jones, R. D., Macleod, A. D., Snell, D. L., Frampton, C. M., \& Anderson, T. J. (2009). Impaired eye movements in post-concussion syndrome indicate suboptimal brain function beyond the influence of depression, malingering or intellectual ability. Brain, 132(Pt 10), 2850-2870. doi:10.1093/brain/awp181

Heyer, G. L., Fischer, A., Wilson, J., MacDonald, J., Cribbs, S., Ravindran, R., ...\& Cuff, S. (2016). Orthostatic Intolerance and Autonomic Dysfunction in Youth With Persistent Postconcussion Symptoms: A Head-Upright Tilt Table Study. Clin J Sport Med, 26(1), 40-45. doi:10.1097/JSM.0000000000000183

Hilz, M. J., Aurnhammer, F., Flanagan, S. R., Intravooth, T., Wang, R., Hosl, K. M., ...\& Koehn, J. (2015). Eyeball pressure stimulation unveils subtle autonomic cardiovascular dysfunction in persons with a history of mild traumatic brain injury. J Neurotrauma, 32(22), 1796-1804. doi:10.1089/neu.2014. 3842

Hilz, M. J., DeFina, P. A., Anders, S., Koehn, J., Lang, C. J., Pauli, E., ...\& Marthol, H. (2011). Frequency analysis unveils cardiac autonomic dysfunction after mild traumatic brain injury. J Neurotrauma, 28(9), 1727-1738. doi:10.1089/neu.2010. 1497

Hilz, M. J., Liu, M., Koehn, J., Wang, R., Ammon, F., Flanagan, S. R., \& Hosl, K. M. (2016). Valsalva maneuver unveils central baroreflex dysfunction with altered blood pressure control in persons with a history of mild traumatic brain injury. $B M C$ Neurol, 16, 61. doi:10.1186/s12883-016-0584-5

Hoehn-Saric, R., \& McLeod, D. R. (1988). The peripheral sympathetic nervous system. Its role in normal and pathologic anxiety. Psychiatr Clin North Am, 11(2), 375-386.

Huang, W., Kutner, N., \& Bliwise, D. L. (2011). Autonomic activation in insomnia: The case for acupuncture. J Clin Sleep Med, 7(1), 95-102.

Hughes, J. W., Feldman, M. E., \& Beckham, J. C. (2006). Posttraumatic stress disorder is associated with attenuated baroreceptor sensitivity among female, but not male, smokers. Biol Psychol, 71(3), 296-302. doi:10.1016/j.biopsycho.2005. 06.002

Hutchison, M. G., Mainwaring, L., Senthinathan, A., Churchill, N., Thomas, S., \& Richards, D. (2017). Psychological and physiological markers of stress in concussed athletes across recovery milestones. J Head Trauma Rehabil, 32(3), E38-E48. doi:10.1097/HTR.0000000000000252

Iverson, G. L. (2005). Outcome from mild traumatic brain injury. Curr Opin Psychiatry, 18(3), 301-317. doi:10.1097/ 01.yco.0000165601.29047.ae

Iverson, G. L., \& Lange, R. T. (2003). Examination of "postconcussion-like" symptoms in a healthy sample. Appl Neuropsychol, 10(3), 137-144. doi:10.1207/S15324826 AN1003_02

Jakola, A. S., Muller, K., Larsen, M., Waterloo, K., Romner, B., \& Ingebrigtsen, T. (2007). Five-year outcome after mild head injury: A prospective controlled study. Acta Neurol Scand, 115(6), 398-402. doi:10.1111/j.1600-0404.2007.00827.x

Jang, S. H., \& Kwon, H. G. (2017). Aggravation of excessive daytime sleepiness concurrent with aggravation of an injured ascending reticular activating system in a patient with mild traumatic brain injury: A case report. Medicine (Baltimore), 96(4), e5958. doi:10.1097/MD.0000000000005958
Jenkins, C. M. (2012). Biofeedback self-regulation training to treat post-concussion headache in a special operations support soldier. J Spec Oper Med, 12(4), 24-27.

Jerath, R., Edry, J. W., Barnes, V. A., \& Jerath, V. (2006). Physiology of long pranayamic breathing: Neural respiratory elements may provide a mechanism that explains how slow deep breathing shifts the autonomic nervous system. Med Hypotheses, 67(3), 566-571. doi:10.1016/j.mehy.2006.02.042

Junger, E. C., Newell, D. W., Grant, G. A., Avellino, A. M., Ghatan, S., Douville, C. M., ...\& Winn, H. R. (1997). Cerebral autoregulation following minor head injury. J Neurosurg, 86(3), 425-432. doi:10.3171/jns.1997.86.3.0425

Kawai, Y., Murthy, G., Watenpaugh, D. E., Breit, G. A., Deroshia, C. W., \& Hargens, A. R. (1993). Cerebral blood flow velocity in humans exposed to $24 \mathrm{~h}$ of head-down tilt. J Appl Physiol (1985), 74(6), 3046-3051

Kenney, M. J., \& Ganta, C. K. (2014). Autonomic nervous system and immune system interactions. Compr Physiol, 4(3), 11771200. doi:10.1002/cphy.c130051

Kirsch, D. L., \& Smith, R. B. (2000). The use of cranial electrotherapy stimulation in the management of chronic pain: A review. NeuroRehabilitation, 14(2), 85-94.

Kitamura, A., Torii, K., Uneyama, H., \& Niijima, A. (2010). Role played by afferent signals from olfactory, gustatory and gastrointestinal sensors in regulation of autonomic nerve activity. Biol Pharm Bull, 33(11), 1778-1782.

Koenig, J., Jarczok, M. N., Ellis, R. J., Hillecke, T. K., \& Thayer, J. F. (2014). Heart rate variability and experimentally induced pain in healthy adults: A systematic review. Eur J Pain, 18(3), 301-314. doi:10.1002/j.1532-2149.2013.00379.x

Kop, W. J., Synowski, S. J., Newell, M. E., Schmidt, L. A., Waldstein, S. R., \& Fox, N. A. (2011). Autonomic nervous system reactivity to positive and negative mood induction: The role of acute psychological responses and frontal electrocortical activity. Biol Psychol, 86(3), 230-238. doi:10.1016/j.biopsycho.2010.12.003

Kopp, W. (2009). Chronically increased activity of the sympathetic nervous system: Our diet-related "evolutionary" inheritance. $J$ Nutr Health Aging, 13(1), 27-29.

Koschke, M., Boettger, M. K., Schulz, S., Berger, S., Terhaar, J., Voss, A., .. \& \& Bar, K. J. (2009). Autonomy of autonomic dysfunction in major depression. Psychosom Med, 71(8), 852-860. doi:10.1097/PSY.0b013e3181b8bb7a

Kraus, J. F., Hsu, P., Schafer, K., \& Afifi, A. A. (2014). Sustained outcomes following mild traumatic brain injury: Results of a five-emergency department longitudinal study. Brain Inj, 28(10), 1248-1256. doi:10.3109/02699052.2014. 916420

Kulshreshtha, P., \& Deepak, K. K. (2013). Autonomic nervous system profile in fibromyalgia patients and its modulation by exercise: A mini review. Clin Physiol Funct Imaging, 33(2), 83-91. doi:10.1111/cpf.12000

La Fountaine, M. F., Gossett, J. D., De Meersman, R. E., \& Bauman, W. A. (2011). Increased QT interval variability in 3 recently concussed athletes: An exploratory observation. J Athl Train, 46(3), 230-233.

La Fountaine, M. F., Heffernan, K. S., Gossett, J. D., Bauman, W. A., \& De Meersman, R. E. (2009). Transient suppression of heart rate complexity in concussed athletes. Auton Neurosci, 148(1-2), 101-103. doi:10.1016/j.autneu.2009.03.001

La Fountaine, M. F., Toda, M., Testa, A., \& Bauman, W. A. (2014). Cardioautonomic instability following a sports-related 
concussion in a 20-year-old male. Int J Cardiol, 172(3), e511512. doi:10.1016/j.ijcard.2014.01.095

La Fountaine, M. F., Toda, M., Testa, A. J., \& Hill-Lombardi, V. (2016). Autonomic nervous system responses to concussion: Arterial pulse contour analysis. Front Neurol, 7, 13. doi:10.3389/fneur.2016.00013

Laborey, M., Masson, F., Ribereau-Gayon, R., Zongo, D., Salmi, L. R., \& Lagarde, E. (2014). Specificity of postconcussion symptoms at 3 months after mild traumatic brain injury: Results from a comparative cohort study. J Head Trauma Rehabil, 29(1), E28-36. doi:10.1097/HTR.0b013e318280f896

Lagarde, E., Salmi, L. R., Holm, L. W., Contrand, B., Masson, F., Ribereau-Gayon, R., ...\& Cassidy, J. D. (2014). Association of symptoms following mild traumatic brain injury with posttraumatic stress disorder vs. postconcussion syndrome. JAMA Psychiatry, 71(9), 1032-1040. doi:10.1001/jamapsychiatry.2014.666

Lagos, L., Thompson, J., \& Vaschillo, E. (2012). Heart rate variability biofeedback for postconcussion syndrome: Implications for treatment. Biofeedback, 41(3), 136-143.

Lagos, L., Thompson, J., \& Vaschillo, E. (2013). A preliminary study: Heart rate variability biofeedback for treatment of postconcussion syndrome. Biofeedback, 41(3), 136-143.

Lambert, E. A., Thompson, J., Schlaich, M., Laude, D., Elghozi, J. L., Esler, M. D., \& Lambert, G. W. (2002). Sympathetic and cardiac baroreflex function in panic disorder. J Hypertens, 20(12), 2445-2451. doi:10.1097/01.hjh. 0000042882.24999 .27

Landre, N., Poppe, C. J., Davis, N., Schmaus, B., \& Hobbs, S. E. (2006). Cognitive functioning and postconcussive symptoms in trauma patients with and without mild TBI. Arch Clin Neuropsychol, 21(4), 255-273. doi:10.1016/j.acn.2005. 12.007

Lange, R. T., Iverson, G. L., Brooks, B. L., \& Rennison, V. L. (2010). Influence of poor effort on self-reported symptoms and neurocognitive test performance following mild traumatic brain injury. J Clin Exp Neuropsychol, 32(9), 961-972. doi:10.1080/13803391003645657

Lannsjo, M., af Geijerstam, J. L., Johansson, U., Bring, J., \& Borg, J. (2009). Prevalence and structure of symptoms at 3 months after mild traumatic brain injury in a national cohort. Brain Inj, 23(3), 213-219. doi:10.1080/02699050902748356

Leddy, J., Hinds, A., Sirica, D., \& Willer, B. (2016). The role of controlled exercise in concussion management. PM R, 8(3 Suppl), S91-S100. doi:10.1016/j.pmrj.2015.10.017

Leddy, J. J., Kozlowski, K., Fung, M., Pendergast, D. R., \& Willer, B. (2007). Regulatory and autoregulatory physiological dysfunction as a primary characteristic of post concussion syndrome: Implications for treatment. NeuroRehabilitation, 22(3), 199-205.

Lee, K. E., Choi, S. E., Kang, J. H., Yim, Y. R., Kim, J. E., Lee, J. W., ...\& Lee, S. S. (2016). Comparison of heart rate variability and classic autonomic testing for detection of cardiac autonomic dysfunction in patients with fibromyalgia. Int J Rheum Dis. doi:10.1111/1756-185X.12858

Lennartsson, A. K., Jonsdottir, I., \& Sjors, A. (2016). Low heart rate variability in patients with clinical burnout. Int J Psychophysiol, 110, 171-178. doi:10.1016/j.ijpsycho.2016.08.005

Leung, A., Shukla, S., Yang, E., Canlas, B., Kadokana, M., Heald, J., ... \& Lee, R. (2016). Diminished supraspinal pain modulation in patients with mild traumatic brain injury. Mol Pain, 12 . doi:10.1177/1744806916662661
Liao, K. H., Sung, C. W., Chu, S. F., Chiu, W. T., Chiang, Y. H., Hoffer, B., ...\& Wang, J. Y. (2016). Reduced power spectra of heart rate variability are correlated with anxiety in patients with mild traumatic brain injury. Psychiatry Res, 243, 349-356. doi:10.1016/j.psychres.2016.07.001

Liberati, A., Altman, D. G., Tetzlaff, J., Mulrow, C., Gotzsche, P. C., Ioannidis, J. P., ...\& Moher, D. (2009). The PRISMA statement for reporting systematic reviews and meta-analyses of studies that evaluate healthcare interventions: Explanation and elaboration. BMJ, 339, b2700. doi:10.1136/bmj. b2700

Losoi, H., Silverberg, N. D., Waljas, M., Turunen, S., RostiOtajarvi, E., Helminen, M., ...\& Iverson, G. L. (2016). Recovery from mild traumatic brain injury in previously healthy adults. J Neurotrauma, 33(8), 766-776. doi:10.1089/ neu.2015.4070

Low, P. A., Tomalia, V. A., \& Park, K. J. (2013). Autonomic function tests: Some clinical applications. J Clin Neurol, 9(1), 1-8. doi:10.3988/jen.2013.9.1.1

Luyer, M. D., Habes, Q., van Hak, R., \& Buurman, W. (2011). Nutritional stimulation of the autonomic nervous system. World J Gastroenterol, 17(34), 3859-3863. doi:10.3748/wjg.v17.i34.3859

MacHale, S. M., Lawrie, S. M., Cavanagh, J. T., Glabus, M. F., Murray, C. L., Goodwin, G. M., \& Ebmeier, K. P. (2000). Cerebral perfusion in chronic fatigue syndrome and depression. $\mathrm{Br}$ J Psychiatry, 176, 550-556.

Machulda, M. M., Bergquist, T. F., Ito, V., \& Chew, S. (1998). Relationship between stress, coping, and postconcussion symptoms in a healthy adult population. Arch Clin Neuropsychol, 13(5), 415-424.

Macleod, A. D. S. (2010). Post concussion syndrome: The attraction of the psychological by the organic. Med Hypotheses, 74(6), 1033-1035. doi:10.1016/j.mehy.2010.01.002

Maes, J., Verbraecken, J., Willemen, M., De Volder, I., van Gastel, A., Michiels, N., ...\& Cluydts, R. (2014). Sleep misperception, EEG characteristics and autonomic nervous system activity in primary insomnia: A retrospective study on polysomnographic data. Int J Psychophysiol, 91(3), 163-171. doi:10.1016/j.ijpsycho.2013.10.012

Marshall, C. M., Vernon, H., Leddy, J. J., \& Baldwin, B. A. (2015). The role of the cervical spine in postconcussion syndrome. Phys Sportsmed, 43(3), 274-284. doi:10.1080/00913847.2015.1064301

Mathew, R. J. (1994). Cerebral blood flow and metabolism in anxiety and anxiety disorders. Indian J Psychiatry, 36(3), 103-120.

Maugans, T. A., Farley, C., Altaye, M., Leach, J., \& Cecil, K. M. (2012). Pediatric sports-related concussion produces cerebral blood flow alterations. Pediatrics, 129(1), 28-37. doi:10.1542/peds.2011-2083

McCraty, R., Atkinson, M., Tiller, W. A., Rein, G., \& Watkins, A. D. (1995). The effects of emotions on short-term power spectrum analysis of heart rate variability. Am J Cardiol, 76(14), 1089-1093.

McCraty, R., Atkinson, M., Tomasino, D., \& Stuppy, W. P. (2001). Analysis of twenty-four hour heart rate variability in patients with panic disorder. Biol Psychol, 56(2), 131-150.

McCrea, M., Iverson, G. L., McAllister, T. W., Hammeke, T. A., Powell, M. R., Barr, W. B., \& Kelly, J. P. (2009). An integrated review of recovery after mild traumatic brain injury (MTBI): Implications for clinical management. Clin Neuropsychol, 23(8), 1368-1390. doi:10.1080/13854040903074652 
McDougal, D. H., \& Gamlin, P. D. (2015). Autonomic control of the eye. Compr Physiol, 5(1), 439-473. doi:10.1002/cphy.c140014

McDougall, S. J., Munzberg, H., Derbenev, A. V., \& Zsombok, A. (2014). Central control of autonomic functions in health and disease. Front Neurosci, 8, 440. doi:10.3389/fnins.2014.00440

McMahon, P., Hricik, A., Yue, J. K., Puccio, A. M., Inoue, T., Lingsma, H. F., .. \& \& Investigators, T.-T. (2014). Symptomatology and functional outcome in mild traumatic brain injury: Results from the prospective TRACK-TBI study. J Neurotrauma, 31(1), 26-33. doi:10.1089/neu.2013.2984

Meier, T. B., Bellgowan, P. S., Singh, R., Kuplicki, R., Polanski, D. W., \& Mayer, A. R. (2015). Recovery of cerebral blood flow following sports-related concussion. JAMA Neurol, 72(5), 530-538. doi:10.1001/jamaneurol.2014.4778

Mickeviciene, D., Schrader, H., Obelieniene, D., Surkiene, D., Kunickas, R., Stovner, L. J., \& Sand, T. (2004). A controlled prospective inception cohort study on the post-concussion syndrome outside the medicolegal context. Eur J Neurol, 11(6), 411-419. doi:10.1111/j.1468-1331.2004.00816.x

Middleton, K., Krabak, B. J., \& Coppel, D. B. (2010). The influence of pediatric autonomic dysfunction on recovery after concussion. Clin J Sport Med, 20(6), 491-492. doi:10.1097/JSM.0b013e3181fac088

Mirow, S., Wilson, S. H., Weaver, L. K., Churchill, S., Deru, K., \& Lindblad, A. S. (2016). Linear analysis of heart rate variability in post-concussive syndrome. Undersea and Hyperbaric Medicine, 43(5), 531-547.

Moher, D., Liberati, A., Tetzlaff, J., Altman, D. G., \& Group, P. (2009). Preferred reporting items for systematic reviews and meta-analyses: The PRISMA statement. PLoS Med, 6(7), e1000097. doi:10.1371/journal.pmed.1000097

Morikawa, Y., Takamoto, K., Nishimaru, H., Taguchi, T., Urakawa, S., Sakai, S., ...\& Nishijo, H. (2017). Compression at myofascial trigger point on chronic neck pain provides pain relief through the prefrontal cortex and autonomic nervous system: A pilot study. Front Neurosci, 11, 186. doi:10.3389/fnins.2017.00186

Morin, M., Langevin, P., \& Fait, P. (2016). Cervical Spine Involvement in Mild Traumatic Brain Injury: A Review. J Sports Med (Hindawi Publ Corp), 2016, 1590161. doi:10.1155/2016/1590161

Mutch, W. A., Ellis, M. J., Ryner, L. N., Ruth Graham, M., Dufault, B., Gregson, B., .. \& \& for The University Health Network Cerebrovascular Reactivity Research, G. (2016). Brain magnetic resonance imaging $\mathrm{CO} 2$ stress testing in adolescent postconcussion syndrome. J Neurosurg, 125(3), 648-660. doi:10.3171/2015.6.JNS15972

Nagamachi, S., Fujita, S., Nishii, R., Futami, S., Wakamatsu, H., Yano, T., ...\& Takasaki, M. (2006). Alteration of regional cerebral blood flow in patients with chronic pain-evaluation before and after epidural spinal cord stimulation. Ann Nucl Med, 20(4), 303-310.

Neurology, A. A. o. (2015). Amendments to the 2011 American Academy of Neurology clinical practice guideline process manual: American Academy of Neurology.

Neurology, A. A. A. O. (2011). Clinical practice guideline process manual. St. Paul, MN: The American Academy of Neurology.

Nordin, L. E., Moller, M. C., Julin, P., Bartfai, A., Hashim, F., \& Li, T. Q. (2016). Post mTBI fatigue is associated with abnormal brain functional connectivity. Sci Rep, 6, 21183. doi:10.1038/srep21183
Norrie, J., Heitger, M., Leathem, J., Anderson, T., Jones, R., \& Flett, R. (2010). Mild traumatic brain injury and fatigue: A prospective longitudinal study. Brain Inj, 24(13-14), 15281538. doi:10.3109/02699052.2010.531687

Novak, P. (2011). Quantitative autonomic testing. J Vis Exp(53). doi:10.3791/2502

Ocon, A. J. (2013). Caught in the thickness of brain fog: Exploring the cognitive symptoms of Chronic Fatigue Syndrome. Front Physiol, 4, 63. doi:10.3389/fphys.2013.00063

Oldenburg, C., Lundin, A., Edman, G., Nygren-de Boussard, C., \& Bartfai, A. (2016). Cognitive reserve and persistent post-concussion symptoms-A prospective mild traumatic brain injury (mTBI) cohort study. Brain Inj, 30(2), 146-155. doi:10.3109/02699052.2015.1089598

Pal, G. K., Velkumary, S., \& Madanmohan. (2004). Effect of short-term practice of breathing exercises on autonomic functions in normal human volunteers. Indian J Med Res, 120(2), 115-121.

Pawelczyk, J. A., Zuckerman, J. H., Blomqvist, C. G., \& Levine, B. D. (2001). Regulation of muscle sympathetic nerve activity after bed rest deconditioning. Am J Physiol Heart Circ Physiol, 280(5), H2230-2239.

Peckerman, A., LaManca, J. J., Qureishi, B., Dahl, K. A., Golfetti, R., Yamamoto, Y., \& Natelson, B. H. (2003). Baroreceptor reflex and integrative stress responses in chronic fatigue syndrome. Psychosom Med, 65(5), 889-895.

Pellman, E. J., Viano, D. C., Casson, I. R., Arfken, C., \& Powell, J. (2004). Concussion in professional football: Injuries involving 7 or more days out-Part 5. Neurosurgery, 55(5), 1100-1119.

Perlmuter, L. C., Sarda, G., Casavant, V., O’Hara, K., Hindes, M., Knott, P. T., \& Mosnaim, A. D. (2012). A review of orthostatic blood pressure regulation and its association with mood and cognition. Clin Auton Res, 22(2), 99-107. doi:10.1007/s10286011-0145-3

Pleuvry, B. J. (2007). Drugs affecting the autonomic nervous system. Anaesthesia and Intensive Care Medicine, 9(2), 84-87.

Rajendra Acharya, U., Paul Joseph, K., Kannathal, N., Lim, C. M., \& Suri, J. S. (2006). Heart rate variability: A review. Med Biol Eng Comput, 44(12), 1031-1051. doi:10.1007/s11517006-0119-0

Rees, C. A. (2014). Lost among the trees? The autonomic nervous system and paediatrics. Arch Dis Child, 99(6), 552-562. doi:10.1136/archdischild-2012-301863

Richter, K. J. (1995). A protocol for managing pain, sleep disorders, and associated psychological sequelae of presumed mild head injury. Journal of Head Trauma Rehabilitation, 10(6), $7-15$.

Rickels, E., von Wild, K., \& Wenzlaff, P. (2010). Head injury in Germany: A population-based prospective study on epidemiology, causes, treatment and outcome of all degrees of head-injury severity in two distinct areas. Brain Inj, 24(12), 1491-1504. doi:10.3109/02699052.2010.498006

Rimel, R. W., Giordani, B., Barth, J. T., Boll, T. J., \& Jane, J. A. (1981). Disability caused by minor head injury. Neurosurgery, 9(3), 221-228.

Robertson, D. (Ed.) (2004). Primer on the autonomic nervous system, 2nd edition. London: Elsevier Academic Press.

Roe, C., Sveen, U., Alvsaker, K., \& Bautz-Holter, E. (2009). Post-concussion symptoms after mild traumatic brain injury: Influence of demographic factors and injury severity in a 1-year cohort study. Disabil Rehabil, 31(15), 1235-1243. doi:10.1080/09638280802532720 
Ropper, A. H., \& Gorson, K. C. (2007). Clinical practice. Concussion. $N$ Engl $J$ Med, 356(2), 166-172. doi:10.1056/NEJMcp064645

Ross, A. J., Medow, M. S., Rowe, P. C., \& Stewart, J. M. (2013). What is brain fog? An evaluation of the symptom in postural tachycardia syndrome. Clin Auton Res, 23(6), 305-311. doi:10.1007/s10286-013-0212-z

Roy, C. S., \& Sherrington, C. S. (1890). On the regulation of the blood-supply of the brain. J Physiol, 11(1-2), 85-158 117.

Ruff, R. L., Riechers, R. G., 2nd, Wang, X. F., Piero, T., \& Ruff, S. S. (2012). For veterans with mild traumatic brain injury, improved posttraumatic stress disorder severity and sleep correlated with symptomatic improvement. J Rehabil Res Dev, 49(9), 1305-1320.

Sams, R., LaBrie, D. W., Norris, J., Schauer, J., \& Frantz, E. (2012). IED blast postconcussive syncope and autonomic dysregulation. Mil Med, 177(1), 48-51.

Sanudo, B., Carrasco, L., de Hoyo, M., Figueroa, A., \& Saxton, J. M. (2015). Vagal modulation and symptomatology following a 6-month aerobic exercise program for women with fibromyalgia. Clin Exp Rheumatol, 33(1 Suppl 88), S41-45.

Schneiderman, A. I., Braver, E. R., \& Kang, H. K. (2008). Understanding sequelae of injury mechanisms and mild traumatic brain injury incurred during the conflicts in Iraq and Afghanistan: Persistent postconcussive symptoms and posttraumatic stress disorder. Am J Epidemiol, 167(12), 1446-1452. doi:10.1093/aje/kwn068

Senthinathan, A., Mainwaring, L. M., \& Hutchison, M. (2017). Heart rate variability of athletes across concussion recovery milestones: A preliminary study. Clin J Sport Med, 27(3), 288295. doi:10.1097/JSM.0000000000000337

Shahim, P., Tegner, Y., Marklund, N., Hoglund, K., Portelius, E., Brody, D. L., ...\& Zetterberg, H. (2017). Astroglial activation and altered amyloid metabolism in human repetitive concussion. Neurology, 88(15), 1400-1407. doi:10.1212/WNL.0000000000003816

Signoretti, S., Vagnozzi, R., Tavazzi, B., \& Lazzarino, G. (2010). Biochemical and neurochemical sequelae following mild traumatic brain injury: Summary of experimental data and clinical implications. Neurosurg Focus, 29(5), E1. doi:10.3171/2010.9.FOCUS10183

Sigurdardottir, S., Andelic, N., Roe, C., Jerstad, T., \& Schanke, A. K. (2009). Post-concussion symptoms after traumatic brain injury at 3 and 12 months post-injury: A prospective study. Brain Inj, 23(6), 489-497. doi:10.1080/02699050902926309

Sinha, S. P., Avcu, P., Spiegler, K. M., Komaravolu, S., Kim, K., Cominski, T., ...\& Pang, K. C. (2017). Startle suppression after mild traumatic brain injury is associated with an increase in pro-inflammatory cytokines, reactive gliosis and neuronal loss in the caudal pontine reticular nucleus. Brain Behav Immun, 61, 353-364. doi:10.1016/j.bbi.2017.01.006

Smith, M. T., Perlis, M. L., Chengazi, V. U., Pennington, J., Soeffing, J., Ryan, J. M., \& Giles, D. E. (2002). Neuroimaging of NREM sleep in primary insomnia: A Tc-99-HMPAO single photon emission computed tomography study. Sleep, 25(3), 325-335.

Smith, M. T., Perlis, M. L., Chengazi, V. U., Soeffing, J., \& McCann, U. (2005). NREM sleep cerebral blood flow before and after behavior therapy for chronic primary insomnia: Preliminary single photon emission computed tomography (SPECT) data. Sleep Med, 6(1), 93-94. doi:10.1016/j.sleep.2004.10.003
Smith-Seemiller, L., Fow, N. R., Kant, R., \& Franzen, M. D. (2003). Presence of post-concussion syndrome symptoms in patients with chronic pain vs mild traumatic brain injury. Brain Inj, 17(3), 199-206.

Sosin, D. M., Sniezek, J. E., \& Thurman, D. J. (1996). Incidence of mild and moderate brain injury in the United States, 1991. Brain Inj, 10(1), 47-54.

Sours, C., Zhuo, J., Roys, S., Shanmuganathan, K., \& Gullapalli, R. P. (2015). Disruptions in resting state functional connectivity and cerebral blood flow in mild traumatic brain injury patients. PLoS One, 10(8), e0134019. doi:10.1371/journal.pone.0134019

Spadoni, A. D., Kosheleva, E., Buchsbaum, M. S., \& Simmons, A. N. (2015). Neural correlates of malingering in mild traumatic brain injury: A positron emission tomography study. Psychiatry Res, 233(3), 367-372. doi:10.1016/j.pscychresns.2015.06.007

Spiegelhalder, K., Fuchs, L., Ladwig, J., Kyle, S. D., Nissen, C., Voderholzer, U., .. \& \& Riemann, D. (2011). Heart rate and heart rate variability in subjectively reported insomnia. J Sleep Res, 20(1 Pt 2), 137-145. doi:10.1111/j.1365-2869.2010.00863.x

Sterling, M. (2011). Whiplash-associated disorder: Musculoskeletal pain and related clinical findings. J Man Manip Ther, 19(4), 194-200. doi:10.1179/106698111X13129729551949

Stocker, R. P. J., Khan, H., Henry, L., \& Germain, A. (2017). Effects of sleep loss on subjective complaints and objective neurocognitive performance as measured by the immediate post-concussion assessment and cognitive testing. Arch Clin Neuropsychol, 32(3), 349-368. doi:10.1093/arclin/acx003

Strebel, S., Lam, A. M., Matta, B. F., \& Newell, D. W. (1997). Impaired cerebral autoregulation after mild brain injury. Surg Neurol, 47(2), 128-131.

Stulemeijer, M., van der Werf, S., Borm, G. F., \& Vos, P. E. (2008). Early prediction of favourable recovery 6 months after mild traumatic brain injury. J Neurol Neurosurg Psychiatry, 79(8), 936-942. doi:10.1136/jnnp.2007.131250

Su, C. F., Kuo, T. B., Kuo, J. S., Lai, H. Y., \& Chen, H. I. (2005). Sympathetic and parasympathetic activities evaluated by heart-rate variability in head injury of various severities. Clin Neurophysiol, 116(6), 1273-1279. doi:10.1016/j.clinph.2005.01.010

Suh, M., Kolster, R., Sarkar, R., McCandliss, B., Ghajar, J., Cognitive, \& Neurobiological Research, C. (2006). Deficits in predictive smooth pursuit after mild traumatic brain injury. Neurosci Lett, 401(1-2), 108-113. doi:10.1016/j.neulet.2006.02.074

Sun, X. Q., Yao, Y. J., Yang, C. B., Jiang, S. Z., Jiang, C. L., \& Liang, W. B. (2005). Effect of lower-body negative pressure on cerebral blood flow velocity during 21 days head-down tilt bed rest. Med Sci Monit, 11(1), CR1-5.

Sundaram, N. K., Geer, E. B., \& Greenwald, B. D. (2013). The impact of traumatic brain injury on pituitary function. Endocrinol Metab Clin North Am, 42(3), 565-583. doi:10.1016/j.ecl.2013.05.003

Sundstrom, T., Guez, M., Hildingsson, C., Toolanen, G., Nyberg, L., \& Riklund, K. (2006). Altered cerebral blood flow in chronic neck pain patients but not in whiplash patients: A 99mTc-HMPAO rCBF study. Eur Spine J, 15(8), 1189-1195. doi:10.1007/s00586-005-0040-5

Sung, C. W., Chen, K. Y., Chiang, Y. H., Chiu, W. T., Ou, J. C., Lee, H. C., . . \& Wang, J. Y. (2016). Heart rate variability and serum level of insulin-like growth factor-1 are correlated with symptoms of emotional disorders in patients suffering a mild 
traumatic brain injury. Clin Neurophysiol, 127(2), 1629-1638. doi:10.1016/j.clinph.2015.08.006

Sung, C. W., Lee, H. C., Chiang, Y. H., Chiu, W. T., Chu, S. F., Ou, J. C., ...\& Wang, J. Y. (2016). Early dysautonomia detected by heart rate variability predicts late depression in female patients following mild traumatic brain injury. Psychophysiology, 53(4), 455-464. doi:10.1111/psyp.12575

Taggart, P., Critchley, H., van Duijvendoden, S., \& Lambiase, P. D. (2016). Significance of neuro-cardiac control mechanisms governed by higher regions of the brain. Auton Neurosci, 199, 54-65. doi:10.1016/j.autneu.2016.08.013

Tahsili-Fahadan, P., \& Geocadin, R. G. (2017). Heart-brain axis: Effects of neurologic injury on cardiovascular function. Circ Res, 120(3), 559-572. doi:10.1161/CIRCRESAHA. 116.308446

Takahashi, C., Hinson, H. E., \& Baguley, I. J. (2015). Autonomic dysfunction syndromes after acute brain injury. Handb Clin Neurol, 128, 539-551. doi:10.1016/B978-0-444-635211.00034-0

Tan, C. O., Meehan 3rd, W. P., Iverson, G. L., \& Taylor, J. A. (2014). Cerebrovascular regulation, exercise, and mild traumatic brain injury. Neurology, 83(18), 1665-1672. doi:10.1212/WNL.0000000000000944

Tan, G., Fink, B., Dao, T. K., Hebert, R., Farmer, L. S., Sanders, A., ...\& Gevirtz, R. (2009). Associations among pain, PTSD, $\mathrm{mTBI}$, and heart rate variability in veterans of Operation Enduring and Iraqi Freedom: A pilot study. Pain Med, 10(7), 1237-1245. doi:10.1111/j.1526-4637.2009.00712.x

Tang, Y. Y., Holzel, B. K., \& Posner, M. I. (2015). The neuroscience of mindfulness meditation. Nat Rev Neurosci, 16(4), 213-225. doi: $10.1038 / \mathrm{nrn} 3916$

Tanriverdi, F., Schneider, H. J., Aimaretti, G., Masel, B. E., Casanueva, F. F., \& Kelestimur, F. (2015). Pituitary dysfunction after traumatic brain injury: A clinical and pathophysiological approach. Endocr Rev, 36(3), 305-342. doi:10.1210/er.20141065

Tanriverdi, F., Unluhizarci, K., \& Kelestimur, F. (2010). Pituitary function in subjects with mild traumatic brain injury: A review of literature and proposal of a screening strategy. Pituitary, 13(2), 146-153. doi:10.1007/s11102-009-0215-x

Tegeler, C. H., Tegeler, C. L., Cook, J. F., Lee, S. W., Gerdes, L., Shaltout, H. A., .. \& \& Simpson, S. L. (2016). A preliminary study of the effectiveness of an allostatic, closed-loop, acoustic stimulation neurotechnology in the treatment of athletes with persisting post-concussion symptoms. Sports Med Open, 2(1), 39. doi:10.1186/s40798-016-0063-y

Temme, L. A., St Onge, P., \& Bleiberg, J. (2016). A history of mild traumatic brain injury affects peripheral pulse oximetry during normobaric hypoxia. Front Neurol, 7, 149. doi:10.3389/fneur.2016.00149

Thayer, J. F., Ahs, F., Fredrikson, M., Sollers 3rd, J. J., \& Wager, T. D. (2012). A meta-analysis of heart rate variability and neuroimaging studies: Implications for heart rate variability as a marker of stress and health. Neurosci Biobehav Rev, 36(2), 747-756. doi:10.1016/j.neubiorev.2011.11.009

Thayer, J. F., Friedman, B. H., \& Borkovec, T. D. (1996). Autonomic characteristics of generalized anxiety disorder and worry. Biol Psychiatry, 39(4), 255-266. doi:10.1016/00063223(95)00136-0

Theadom, A., Parag, V., Dowell, T., McPherson, K., Starkey, N., Barker-Collo, S., ...\& Group, B. R. (2016). Persistent problems 1 year after mild traumatic brain injury: A longitudinal population study in New Zealand. Br J Gen Pract, 66(642), e16-23. doi:10.3399/bjgp16X683161

Thiagarajan, P., \& Ciuffreda, K. J. (2015). Pupillary responses to light in chronic non-blast-induced mTBI. Brain Inj, 29(12), 1420-1425. doi:10.3109/02699052.2015.1045029

Thompson, M., Thompson, L., \& Reid-Chung, A. (2015). Treating postconcussion syndrome with LORETA Z-score neurofeedback and heart rate variability biofeedback: Neuroanatomical/neurophysiological rationale, methods, and case examples. Biofeedback, 43(1), 15-26.

Thornhill, S., Teasdale, G. M., Murray, G. D., McEwen, J., Roy, C. W., \& Penny, K. I. (2000). Disability in young people and adults one year after head injury: Prospective cohort study. BMJ, 320(7250), 1631-1635.

Tiersky, L. A., Cicerone, K. D., Natelson, B. H., \& DeLuca, J. (1998). Neuropsychological functioning in chronic fatigue syndrome and mild traumatic brain injury: A comparison. The Clinical Neuropsychologist, 12(4), 503-512.

Trahan, D. E., Ross, C. E., \& Trahan, S. L. (2001). Relationships among postconcussional-type symptoms, depression, and anxiety in neurologically normal young adults and victims of mild brain injury. Arch Clin Neuropsychol, 16(5), 435-445.

Truong, J. Q., \& Ciuffreda, K. J. (2016a). Comparison of pupillary dynamics to light in the mild traumatic brain injury (mTBI) and normal populations. Brain Inj, 30(11), 1378-1389. doi:10.1080/02699052.2016.1195922

Truong, J. Q., \& Ciuffreda, K. J. (2016b). Objective pupillary correlates of photosensitivity in the normal and mild traumatic brain injury populations. Mil Med, 181(10), 1382-1390. doi:10.7205/MILMED-D-15-00587

Truong, J. Q., \& Ciuffreda, K. J. (2016c). Quantifying pupillary asymmetry through objective binocular pupillometry in the normal and mild traumatic brain injury (mTBI) populations. Brain Inj, 30(11), 1372-1377. doi:10.1080/02699052.2016.1192220

Tsigos, C., Kyrou, I., Kassi, E., \& Chrousos, G. P. (2000). Stress, endocrine physiology and pathophysiology. In L.J. De Groot, G. Chrousos, K. Dungan, K.R. Feingold, A. Grossman, J.M. Hershman, C. Koch, M. Korbonits, R. McLachlan, M. New, J. Purnell, R. Rebar, F. Singer, \& A. Vinik (Eds.), Endotext. South Dartmouth (MA).

Ulrich-Lai, Y. M., \& Herman, J. P. (2009). Neural regulation of endocrine and autonomic stress responses. Nat Rev Neurosci, 10(6), 397-409. doi:10.1038/nrn2647

van Noordt, S., \& Good, D. (2011). Mild head injury and sympathetic arousal: Investigating relationships with decision-making and neuropsychological performance in university students. Brain Inj, 25(7-8), 707-716. doi:10.3109/02699052.2011.580312

Vasic, N., Wolf, N. D., Gron, G., Sosic-Vasic, Z., Connemann, B. J., Sambataro, F., .. \&\& Wolf, R. C. (2015). Baseline brain perfusion and brain structure in patients with major depression: A multimodal magnetic resonance imaging study. J Psychiatry Neurosci, 40(6), 412-421.

Vasterling, J. J., Brailey, K., Proctor, S. P., Kane, R., Heeren, T., \& Franz, M. (2012). Neuropsychological outcomes of mild traumatic brain injury, post-traumatic stress disorder and depression in Iraq-deployed US Army soldiers. Br J Psychiatry, 201(3), 186-192. doi:10.1192/bjp.bp.111.096461

Vavilala, M. S., Lee, L. A., Boddu, K., Visco, E., Newell, D. W., Zimmerman, J. J., \& Lam, A. M. (2004). Cerebral 
autoregulation in pediatric traumatic brain injury. Pediatr Crit Care Med, 5(3), 257-263.

Vgontzas, A. N., Tsigos, C., Bixler, E. O., Stratakis, C. A., Zachman, K., Kales, A., ...\& Chrousos, G. P. (1998). Chronic insomnia and activity of the stress system: A preliminary study. J Psychosom Res, 45(1), 21-31.

Waldron-Perrine, B., Tree, H. A., Spencer, R. J., Suhr, J., \& Bieliauskas, L. (2015). Informational literature influences symptom expression following mild head injury: An analog study. Brain Inj, 29(9), 1051-1055. doi:10.3109/02699052.2015.1004742

Wang, X., Xie, H., Cotton, A. S., Brickman, K. R., Lewis, T. J., Wall, J. T., .. \& \& Liberzon, I. (2017). Early changes in cortical emotion processing circuits after mild traumatic brain injury from motor vehicle collision. J Neurotrauma, 34(2), 273-280. doi:10.1089/neu.2015.4392

Wang, Y., Nelson, L. D., LaRoche, A. A., Pfaller, A. Y., Nencka, A. S., Koch, K. M., \& McCrea, M. A. (2016). Cerebral blood flow alterations in acute sport-related concussion. J Neurotrauma, 33(13), 1227-1236. doi:10.1089/neu.2015.4072

Weyer Jamora, C., Schroeder, S. C., \& Ruff, R. M. (2013). Pain and mild traumatic brain injury: The implications of pain severity on emotional and cognitive functioning. Brain Inj, 27(10), 1134-1140. doi:10.3109/02699052.2013.804196

Wofford, K. L., Harris, J. P., Browne, K. D., Brown, D. P., Grovola, M. R., Mietus, C. J., ...\& Cullen, D. K. (2017). Rapid neuroinflammatory response localized to injured neurons after diffuse traumatic brain injury in swine. Exp Neurol, 290, 85-94. doi:10.1016/j.expneurol.2017.01.004
Won, E., \& Kim, Y. K. (2016). Stress, the autonomic nervous system, and the immune-kynurenine pathway in the etiology of depression. Curr Neuropharmacol, 14(7), 665-673.

Wong, J. L., Regennitter, R. P., \& Barrios, F. (1994). Base rate and simulated symptoms of mild head injury among normals. Arch Clin Neuropsychol, 9(5), 411-425.

Ye, J. J., Lee, K. T., Lin, J. S., \& Chuang, C. C. (2017). Observing continuous change in heart rate variability and photoplethysmography-derived parameters during the process of pain production/relief with thermal stimuli. J Pain Res, 10, 527-533. doi:10.2147/JPR.S129287

Yoshiuchi, K., Farkas, J., \& Natelson, B. H. (2006). Patients with chronic fatigue syndrome have reduced absolute cortical blood flow. Clin Physiol Funct Imaging, 26(2), 83-86. doi:10.1111/j.1475-097X.2006.00649.x

Zagorchev, L., Meyer, C., Stehle, T., Wenzel, F., Young, S., Peters, J., ...\& McAllister, T. (2016). Differences in regional brain volumes two months and one year after mild traumatic brain injury. $J$ Neurotrauma, 33(1), 29-34. doi:10.1089/neu.2014.3831

Zumstein, M. A., Moser, M., Mottini, M., Ott, S. R., SadowskiCron, C., Radanov, B. P., ...\& Exadaktylos, A. (2011). Long-term outcome in patients with mild traumatic brain injury: A prospective observational study. J Trauma, 71(1), 120-127. doi:10.1097/TA.0b013e3181f2d670 